\title{
1 Expanding the gestural model of lexical tone: evidence from two dialects of Serbian \\ 2
}

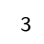

4

\section{- Abstract}

7 Featural and gestural models of tone differ on the degree to which they include timing
8

\author{
Robin Karlin — UW-Madison
}

December 10, 2020 tones and their tone-bearing units, where featural models emphasize the role of acoustic relationships and gestural models instead emphasize articulatory coordination. We present the results of two acoustic production studies on two dialects of Serbian, a lexical pitch accent language. In the Belgrade dialect, pitch accents are aligned relatively late in the tone-bearing unit, while in the Valjevo dialect, pitch accents are phonetically retracted, sometimes into the preceding syllable. We varied the syllable onsets of tone-bearing units in falling (experiment 1) and rising (experiment 2) pitch accents, and measured the effects on F0 contours. Despite these differences in phonetic alignment, the phonological system is the same in both dialects. We argue that this apparent mismatch between the phonology by allowing tone gestures to coordinate with other gestures in all the ways that segmental gestures can, rather than restricting tone to c-center coordination. and phonetics can be expressed straightforwardly in the Articulatory Phonology framework 


\section{Introduction}

Featural and gestural models of representation disagree on the degree to which specific timing information should be included in the phonological representation. In lexical tone, this difference is particularly relevant, as the question of how to generate the phonetic timing of tone contours from a temporally impoverished phonological representation has long been a topic of debate in phonological theory. In featural models, the main goal is to represent contrast, and phonetic timing is relegated to the domain of phonetic mapping rules. In gestural models, it is impossible to represent any atom of speech without including a temporal component, which directly specifies the phonetic result. In lexical tone, the line between these two types of of representational theory can be blurred, as contrasts that utilize only differences in temporal alignment relative to some tone-bearing unit need to be captured. However, the tools available to featural theories of tonal representation and gestural theories of representation predict a different set of relationships between tone contours and their tone-bearing units.

In this paper, I argue for the utility of a gestural model of tone, where detailed timing information is included in the phonological representation, and further the Articulatory Phonology models of lexical tone to include more coordinative modes and thus predict more data. I present data from two acoustic studies on two varieties of Serbian, one with late alignment of accentual peaks and one with early alignment, and show that they share a phonological system but have distinct phonetic realizations. Articulatory Phonology is the best equipped to capture these facts: both abstract phonological relationships and phonetic realization can be derived from coordinative relationships, where the presence of a coordinative relationship between two gestures indicates phonological relatedness and the precise nature of that coordinative relationship predicts the phonetics. I also expand on the gestural model of tone and show that tonal coordination is more diverse than what has been previously hypothesized, and propose that tone gestures can be coordinated in all the same manners as segmental gestures.

\section{$1.1 \quad$ Featural models}

In Autosegmental-Metrical theory, words are typically lexically specified for tone, but the phonetic realization and alignment of tones with the segmental material is determined through two stages. First, the association of a tone to a segment (or segmental structure) is not underlying, but rather part of the derivation from underlying to surface form. The unit that tone targets can be associated to is language-specific, and is referred to as the 
tone-bearing unit (henceforth, TBU); the vowel, mora, and syllable have been proposed for various languages (DiCanio, Amith, and García 2014; Ladd 2008; Morén and Zsiga 2006; Yip 2002, inter alia). In this use of the TBU, phonological distribution plays a major role in determining the TBU for a particular language.

Timing information in AM representations is sparse, dealing only with linear ordering within tiers (e.g., H before L). The association of a tone to a TBU implies some sort of acoustic overlap (Sagey 1986), but the precise alignment is the domain of phonetic mapping rules. These mapping rules are highly idiosyncratic to individual languages and thus it is difficult - if not impossible - to predict the phonetic form from underlying tones. For intonation and pitch accent languages, one of the most widely investigated hypotheses for phonetic mapping is the segmental anchoring hypothesis, first formally proposed by Ladd, Faulkner, Faulkner, and Schepman (1999). Segmental anchoring hypothesizes an alignment of tunes to segmental material, which remains stable in the face of pressures such as speech rate. It specifically hypothesizes that both the start and the target of a pitch excursion are anchored to the segmental string - that is, for any rise or fall in F0, there is an anchoring point for the minimum as well as for the maximum (Prieto 2011). Possible anchors are limited to the TBU, thus constraining the possible realizations of any given tone-to-TBU association. Similar mapping rules have also been invoked for lexical tone languages; for example, Morén and Zsiga (2006) argued that a moraic TBU is responsible for phonetic alignment in Thai, in that the tone associated to the TBU is exceptionlessly realized at the right edge of that TBU.

However, it is not uncommon for pitch targets to occur outside their TBU. Late pitch targets have been attributed to so-called 'peak delay', a phenomenon where pitch targets are achieved after the TBU they are associated to (Xu 2001). Peak delay has been documented in several languages, including lexical tone languages (see Myers 1999 for Chichewa; Xu 2001 for Mandarin; Morén and Zsiga 2006 for Thai), as well as in intonation-only languages (see Silverman and Pierrehumbert 1990 for English; Arvaniti, Ladd, and Mennen 1998 for Greek). Peak delay is so ubiquitous that it is encoded in the PENTA model of speech melody (Xu 2005; Xu \& Wang 2001), where the model predicts that all pitch turning points occur after the end of the TBU due to inertia.

There are comparatively fewer cases of an early peak. In tonal crowding, peaks occur early relative to the TBU; however, it specifically describes circumstances where pitch targets are shifted to the left due to tonal pressures from the right, such as the addition of a boundary tone (Arvaniti, Ladd, \& Mennen 2006). This is distinct from early peaks that occur without additional time pressure, such as those described by Bruce (1977) for Stockholm Swedish. In Swedish, both accent I and accent II are characterized by an $\mathrm{H}$ target (F0 peak); the 
two accents are distinguished by timing, where accent I peaks occur earlier relative to the stressed syllable than accent II peaks. The case of Swedish accent I is quite extreme, as accent I "occurs as early as in the pre-stress syllable, even if this syllable belongs to a preceding word" (p. 46; 49) - that is, the accentual peak can occur so early that it leaves the phonological word entirely.

The delegation of alignment to the phonetic domain is due largely to a dearth of languages that contrast timing in tone; contrastive alignment within a syllable was hypothesized to not be possible (Hyman 1988, as cited in Remijsen and Ayoker 2014). However, recent studies on Shilluk (Remijsen \& Ayoker 2014), Dinka (Remijsen 2013), and Yoloxóchitl Mixtec (DiCanio et al. 2014) have provided examples of such contrastive alignment, suggesting that more detailed timing information may be necessary for tonal representation.

Contrasts in alignment in intonation have lead to the introduction of the star convention to indicate which tone is anchored to the stressed syllable. For example, Pierrehumbert (1980) described two distinct rises in English: an early rise, denoted as $\mathrm{L}+\mathrm{H}^{*}$, and a late rise, denoted as $\mathrm{L}^{*}+\mathrm{H}$. The early rise is created by a leading $\mathrm{L}$ tone with the transition to the $\mathrm{H}$ on the stressed syllable, while in the late rise, the $\mathrm{L}$ is aligned to the stressed syllable, and the transition to H trails after. Examples in lexical tone languages include Smiljanić's (2002) proposal of two pitch accents for Serbian, $\mathrm{L}+\mathrm{H}^{*}$ and $\mathrm{L}^{*}+\mathrm{H}$, which represent early (falling accent) and late (rising accent) F0 rises, respectively; Myrberg (2010) (after Bruce 1977) addressed the alignment differences in the Swedish accentual system using this convention as well, proposing $\mathrm{HL}^{*}$ for accent I and $\mathrm{H}^{*} \mathrm{~L}$ for accent II. In proposing a bitonal HL* pitch accent, this model accounts for a peak seemingly occurring outside the domain of its TBU: the $\mathrm{L}$ of the HL pitch accent is anchored to the stressed syllable in accent I, which leaves $\mathrm{H}$ to occur earlier. However, the star convention has been used even in non-contrastive cases, where it is actually being used to express phonetic alignment information instead (Prieto 2011). The inclusion of alignment information in autosegmental representations has blurred the line between time-inclusive and time-exclusive theories of representation; more pressingly, with more examples of timing-based contrasts, it has become increasingly necessary to consider including timing information in the representation.

\subsection{Gestural approaches}

Rather than using features as point values on a string, Articulatory Phonology (AP) uses gestures as the fundamental unit of contrast (Browman \& Goldstein 1990, 1992, 1986). Gestures are, importantly, specified in both space and time; gestures can contrast from each other in either dimension. Recently, tone has also fruitfully been treated as a gesture (Gao 
2008; Karlin 2014; Mücke, Nam, Hermes, \& Goldstein 2011; Prieto, Mücke, Becker, \& Grice 2007; Yi 2014, 2017). The space dimension is mapped in F0 space, as that is the linguistically relevant variable, rather than some laryngeal posture. Thus, a High tone gesture would have some (relatively) high F0 target, and a Low tone gesture would have some low F0 target.

Timing information comes from two sources, and the acoustic linearization can then be derived from the combined spatial and temporal details included in a gestural constellation. First, any individual gesture is specified with some stiffness, which is an abstraction of duration analogous to spring stiffness (Browman \& Goldstein 1986; Fuchs, Perrier, \& Hartinger 2011). Gestures with high stiffness values have a shorter duration, while gestures with low stiffness values have longer durations. The second source of timing is the relative timing of gestures to each other, which is achieved through the coordination of two or more gestures into a "constellation". There are two basic modes of coordination in AP: in-phase coordination, which is when two gestures start at the same time, and anti-phase coordination, which is when two gestures are $180^{\circ}$ out of phase with each other. Gafos (2002) has argued that segmental gestures can be coordinated at various points in the gestural trajectory, including the onset, target attainment, release, and c-center (midpoint of gestural plateau), which provides a larger possible set of alignments than exclusively onset-to-onset coordination, while still being constrained.

The most relevant type of gestural constellation for tone is the "c-center", first described for consonant clusters (Browman \& Goldstein 1988; Goldstein, Chitoran, \& Selkirk 2007; Marin 2013; Marin \& Pouplier 2010). This structure utilizes both basic coordinative modes; there are two consonant closure gestures in-phase coordinated with a vowel, and anti-phase with each other (illustrated in Figure 1). In this case, the two consonantal gestures repel each other, since they want to be at opposite sides of their cycle, but they are simultaneously pulled together because they both want to be in-phase with the vowel. The result is that the onset of the vocalic gesture is coordinated with the gestural center of the consonantal gestures, instead of with the onset of one consonant gesture, as is typical in CV syllables (Browman \& Goldstein 1988). This pattern has been found in tone languages as well, such as Mandarin (Gao 2008; Yi 2014, 2017; Zhang, Geissler, \& Shaw 2019) and the first tone gesture in Thai contour tones (Karlin 2014). In tone languages, instead of a second consonant gesture, there is a tone gesture, and that tone gesture causes the same shifts in timing as a consonant gesture would.

However, this same structure has not been verified in intonation languages thus far (Mücke, Grice, Becker, \& Hermes 2009; Mücke et al. 2011; Prieto et al. 2007). Instead, the timing of pitch gestures in intonational languages patterned with in-phase coordination: the pitch gesture, consonant gesture, and vowel gesture all started at the same time. Based 


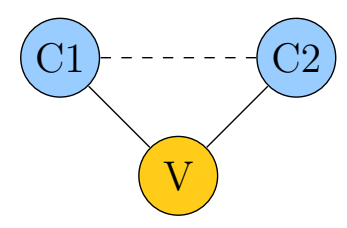

(a) C-center structure with two consonants.

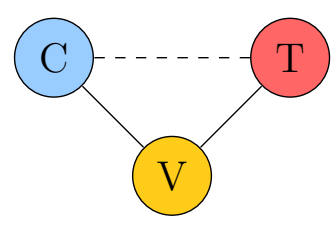

(b) C-center structure with one consonant and one tone gesture.

Figure 1: Gestural score schematics for c-center, with either two onset consonants or a simple onset with tone gesture. Dashed lines represent anti-phase coordination; solid lines indicate in-phase coordination (gestural onset to gestural onset).

on these findings, Mücke et al. (2011) proposed that lexical tone languages exclusively use the c-center structure for tone coordination, while intonation uses in-phase coordination. The argument is that tone gestures are directly integrated with the lexical representation of the word, and as such have the same status as segmental gestures; they can thus influence the structure of the syllable constellation itself. In contrast, intonation is not thought to be part of the representation of the word (though for counterarguments in the framework of exemplar theory, see Schweitzer et al. 2015); consequently, the gestures do not directly coordinate with the segmental gestures, but rather are "overlaid" after the gestural constellation for the syllable is already established.

The articulatory model of phonological representation eliminates the need for mapping rules from phonology to phonetics. For tone, this eliminates the need for mapping rules such as aligning an $\mathrm{H}$ target to either the right or left edge of a TBU based on a binary relationship between a tone and its TBU (i.e., either there is a relationship or there is not). Even within the realm of a tone being coordinated to its TBU, there are multiple ways to be phonetically timed. However, the timing of pitch gestures is also bound by the two basic coordinative modes. The c-center hypothesis for tone further restricts the possible set of phonetic realizations. Much like AM theory, this rules out systems where pitch trajectories are realized fully outside the TBU-particularly when the target is achieved before the beginning of the TBU.

However, the body of literature addressing pitch as a potential articulatory gesture remains relatively small, and thus the c-center hypothesis for tone is largely untested. First, only a few languages have been investigated: prior to the development of the c-center hypothesis for tone, the author is only aware of work on Mandarin and some speculation on Thai (Gao 2008); since then, there has been additional work on Mandarin Yi (2014, 2017); 


\footnotetext{
${ }^{1}$ In this list I am providing the accentual symbols according to the Serbian tradition; for the rest of this chapter, I will provide IPA when necessary alongside the orthography.
}

Zhang et al. (2019) and Thai (Karlin 2014), and ongoing work on Tibetan (Geissler 2019).
This is problematic for two reasons. First, it is a rather large leap to generalize from two an Indo-European language with lexical pitch accent.

\subsection{Language of study: Serbian}

Serbian (srb) is a South Slavic (Indo-European) language with lexical pitch accent. The term "accent" has been used in the Serbian literature to describe different phenomena in the prosodic system of Serbian, but most typically refers to a joint stress-length-pitch phenomenon of prominence. According to traditional accounts, Serbian has four accent types that contrast on stressed syllables (Lehiste \& Ivić 1986): short falling (e.g. lüka 'onion.GEN') ${ }^{1}$; short rising (e.g. lùla 'smoking pipe'); long falling (e.g. Lûka 'Luka (name)'); and long rising (e.g. lúka 'harbor'). All words in Serbian, excluding function words such as clitics and prepositions, have one primary stress, and thus one accent (Zec 2005).

The names of the accents are indicative of the bundle of prosodic characteristics that have been included in the term "accent". The length descriptors refer to the phonological length of the vowel in the "accented" syllable: short accents have a short vowel, and long accents have a long vowel. The pitch descriptor refers, generally speaking, to the pitch contour of the "accented" syllable: falling accents start high and fall, while rising accents start low and rise. Schemata for the four accent types are provided in blue in Figure 2 (Lehiste and Ivić 1986, and references therein), as they would be produced in trisyllabic words with "accent" on the first syllable.

There are currently two major autosegmental proposals for the representation of the Serbian accentual system. For this paper, I take as a starting point the analysis presented by Inkelas and Zec (1988), who argue that Serbian accent is most fruitfully treated as a $\mathrm{H}$ (igh) pitch that determines the location of stress. In this analysis, the location of the $\mathrm{H}$ is lexically specified, and stress is located one syllable to the left. This accounts for the contour of rising accents, where the stressed syllable is lower in pitch than the following syllable. Falling accents occur when the $\mathrm{H}$ is assigned to the first syllable, and thus the contour falls from the stressed syllable. This analysis also accounts for the distribution of

\begin{abstract}
languages (Mandarin and Thai) to thousands of tone languages. Second, these two languages are not related to each other but they do come from similar types of tone systems (i.e., they are both Asian tone languages). Furthermore, the leap was made after discovering that a handful of European intonational systems did not have the c-center, which is problematic for similar reasons. This paper aims to fill these gaps by comparing two dialects of Serbian,
\end{abstract}


accents in Serbian: rising accents can occur on any (non-final) syllable, but falling accents can only occur initially, since the stress cannot move one syllable to the left of an initial $\mathrm{H}$. The four Serbian accents can be broken down and described as in Table 1.

Table 1: A breakdown of the features of the four Serbian accents as they occur on initial syllables, following Inkelas and Zec 1988. The lexical H is noted as a subscript after the syllable it is assigned to.

\begin{tabular}{|c|c|c|c|c|c|c|}
\hline Accent & Vowel & Stress & Pitch & Phonology & Orthography & Gloss \\
\hline Short falling & short & initial & initial & $/ / \mathrm{lu}_{H} \mathrm{ka} /$ & lüka & 'onion.GEN' \\
\hline Short rising & short & initial & second & $/$ 'lula $\mathrm{l}_{H} /$ & lùla & 'smoking pipe' \\
\hline Long falling & long & initial & initial & $/$ 'lus $\mathrm{s}_{H} \mathrm{ka} /$ & Lûka & 'Luka (name)' \\
\hline Long rising & long & initial & second & $/$ 'lurka ${ }_{H} /$ & lúka & 'harbor' \\
\hline
\end{tabular}

The main alternative analysis utilizes the star convention to express the contrast between rising and falling accents, but associates both pitch accents to the stressed syllable. Smiljanić (2002) analyzed the Serbian ${ }^{2}$ tone system in terms of pitch melodies: rising accents are $\mathrm{L}^{*}+\mathrm{H}$, while falling accents are $\mathrm{L}+\mathrm{H}^{*}$. That is, rising accents have an $\mathrm{L}$ anchored to the stressed syllable, followed by an unanchored $\mathrm{H}$, while falling accents have an $\mathrm{H}$ anchored to the stressed syllable, which is preceded by an unanchored L. This analysis was based on observations of the alignment of pitch extrema with acoustic segment boundaries, but fails to account for the phonological distribution of accents; under this account, there would have to be a specific restriction in the phonology that forbids falling accents $\left(\mathrm{L}+\mathrm{H}^{*}\right)$ on non-initial syllables (cf. Zsiga and Zec 2013).

Of particular scientific interest are the Belgrade and Valjevo dialects of Serbian, which are typically assumed to have the same phonological system of contrast, but with different phonetic realizations. Under the Inkelas and Zec (1988) analysis, Belgrade F0 peaks occur near the end of the TBU the lexical $\mathrm{H}$ is associated to, while Valjevo F0 peaks occur near or even before the beginning of the TBU. Zec and Zsiga (2016) describe "variable retraction" of the Valjevo rising accents in phrase-initial position ${ }^{3}$ : for two of the three Valjevo speakers, the F0 peak occurred on the post-stress syllable $50 \%$ of the time, and was otherwise retracted to the stressed syllable. For the remaining speaker, the F0 peak consistently occurred on the stressed syllable. In the Belgrade dialect, F0 peaks of rising accents are consistently realized on the post-tonic syllable.

\footnotetext{
${ }^{2}$ As spoken in Belgrade.

${ }^{3}$ In phrase-final position, both Belgrade and Valjevo dialects shift a $\mathrm{H}$ peak onto the preceding syllable due to tonal crowding.
} 


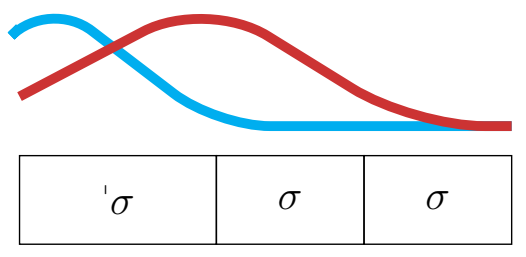

(a) Short falling

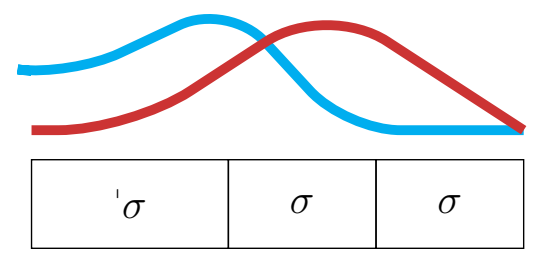

(b) Short rising

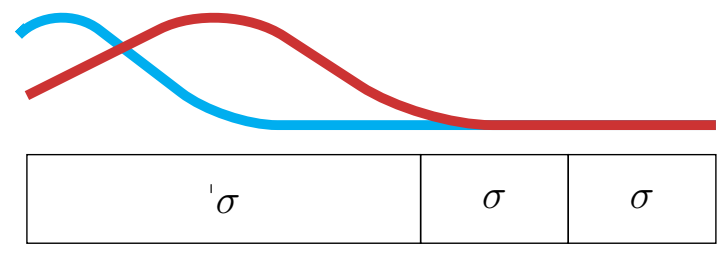

(c) Long falling

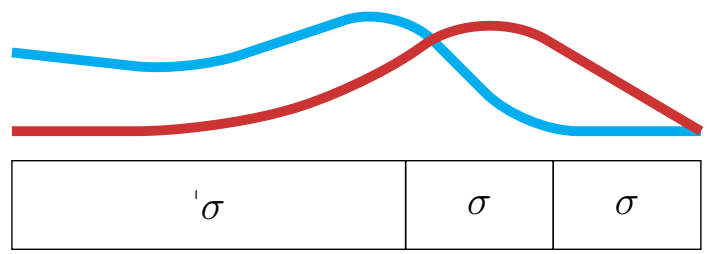

(d) Long rising

Figure 2: Schemata of the F0 movements for the four accent types on trisyllabic words, comparing Belgrade (red) and Valjevo (blue) dialects. Contours adapted from Zec and Zsiga 2016.

\subsection{This study}

There are two possible explanations for the retraction in Valjevo rising accents: either the Valjevo dialect has undergone a phonological shift, where all lexical H tones are associated to stressed syllables, and the contrast between rising and falling accents is one of alignment alone, or early peak alignment is simply a phonetic characteristic of Valjevo pitch accents. Both possibilities raise theoretical issues in both autosegmental and gestural theories. In order to address these questions, I present the results of two acoustic studies on these dialects of Serbian. In the first study, I examine the timing of falling accent contours, which are uncontroversially associated to the initial syllable. In the second study, I compare the baseline of falling accents to the timing of rising accents contours, which are more controversial. I also test the c-center hypothesis for tone, expanding the set of lexical tone languages which have been analyzed under an Articulatory Phonology lens.

\section{Experiment 1: Falling accents}

In this experiment, I focus on the falling accent contour and establish the relationship between the segmental content of a TBU and F0 timing. The falling accents are rather uncon- 
troversial compared to rising accents; both the Inkelas and Zec (1988) and Smiljanić (2002) analyses agree that a $\mathrm{H}$ (igh) tone of some sort is associated to an initial stressed syllable. Furthermore, although the Valjevo dialect exhibits peak retraction in both accent contours, in falling accents the peak still occurs within the first syllable. Thus, the behavior of the falling accents can serve as a basic case to help interpret the behavior of the rising accents (in Section 3).

\subsection{Methods}

\subsubsection{Participants}

Data was collected from a total of 24 participants (13 Belgrade, 11 Valjevo). Speakers of the Belgrade dialect were all born and raised in Belgrade, though typically one or both parents were from elsewhere. Speakers of the Valjevo dialect had all been raised in Valjevo, but were currently studying in Belgrade. Since living in Belgrade for an extended amount of time affects the realization of accent, the Valjevo speakers were all young university students that still had family ties in Valjevo and frequently visited home. One Valjevo participant was excluded after data collection when it was determined that they had already accommodated their accentual production to the Belgrade dialect.

Several additional exclusions had to be made. The bulk of exclusions were due mainly to frequent errors, either improper focus placement (seven participants), which made it impossible to find accentual peaks in the target word, or errors in segmental or accentual production or both (three participants). There were two particularly problematic words, due to sharing orthographic representation with existing words: first, the word rave with a long rising accent (rather than the long falling accent desired) is a slang term that means 'whore.ACC.PL'; second, the word lave with a long rising accent (again, instead of the desired long falling accent) means 'lava.GEN'. Participants were typically consistent with their pronunciation; there were participants that always used the wrong accent, even after reminders, and participants that always remembered the correct and novel accent. Participants that used the wrong accent were excluded.

The final dataset includes data from 13 participants: 5 speakers of Belgrade Serbian (ages 19-39; 3M, 2F) and 8 speakers of Valjevo Serbian (ages $19-22 ; 2 \mathrm{M}, 6 \mathrm{~F}$ ).

\subsubsection{Target words}

Target words were formed from three base words, where the first syllable onset of these words was varied to create a set of five rhyming words, using three simple onsets /r, l, m/ and two complex onsets /mr, ml/: mrâve /'mra: ${ }_{H} \mathrm{ve/}$ 'ant.ACC.PL' (derived words: râve, 
lâve, mâve, mlâve); mrämor /'mra ${ }_{H}$ mor/ 'marble' (derived words: rämor, lämor, mämor, mlämor); mrämora /'mra ${ }_{H}$ mora/ 'marble.GEN' (derived words: rämora, lämora, mämora, mlämora). ${ }^{4}$ These onsets vary in phonetic duration, allowing investigation of phonetic effects of different syllable onsets.

Since Serbian typically does not mark any aspect of accent in its orthography, participants received a list of words that would be used in the study, which marked the accents using dictionary conventions and grouped them together to make clear what accents they had. They were informed that the nonce words were supposed to be a "perfect rhyme" with the real word it looked like, i.e. that they had the same pitch accent. They were also told that the nonce words were supposed to refer to other things in the same lexical category as the real word - e.g. since mrämor was a type of stone, mlämor, mämor, lämor, and rämor were other types of stone. Participants were allowed to reference a sheet with accents and definitions through the study, though none had to.

\subsubsection{Carrier phrases}

In order to prevent boredom and consequent list intonation, there were two carrier phrases in this study: nêmamo $X$ /'ne: ${ }_{H}$ mamo/ 'we don't have $\mathrm{X}$ ' and imamo $X /$ 'ima(: $)_{H}$ mo/ 'we have $\mathrm{X}^{\prime}$ ). In the full experiment there were 50 phrases total ( 5 accent types $\mathrm{x} 5$ syllable onsets x 2 carrier phrases); this paper analyzes just the falling accents, which were 30 of these phrases.

\subsubsection{Task}

During the experiment, participants first heard a spoken prompt, which was recorded by a native speaker of Belgrade Serbian. The prompt either claimed that there were no instances of a lexical category (e.g., Nemamo mineral ni na jednoj slici 'We don't have a mineral in any picture') or that they had all instances of a lexical category (e.g., Imamo slike $z a$ sve minerale 'We have pictures for all of the minerals'). The participant then responded in disagreement with a written response that was presented on the screen. In order to prevent overlap, rushing, and list intonation, the written response only appeared on the screen after the context prompt ended.

The 50 sentences were put in random order and then split into two groups of 25 , creating two blocks to prevent fatigue (thus, one round of the experiment had two blocks with 25

\footnotetext{
${ }^{4}$ The full experiment also included a set of short rising words (base word mravinjak 'anthill') as well as a set of long rising words (base word Monu 'Mona.ACC (clothing brand)'; however, they are excluded from the present analysis as the location of syllable onset variation was not informative for determining the phonological association of rising accents.
} 
trials each). After the two blocks were completed, the 50 sentences were randomized again, instead of repeating the first random order. The experiment repeated for three rounds, for a total of 150 sentences.

The experiment was presented in PsychoPy. Due to difficulties triggering clean recordings with native PsychoPy tools, the experiment was recorded in Audacity as one sound file with a Samson GoMic.

\subsection{Data labeling and analysis}

\subsubsection{Segmentation}

Data was initially aligned with the Montreal Forced Aligner (McAuliffe, Socolof, Mihuc, Wagner, \& Sonderegger 2017), and then corrected by hand in Praat (Boersma \& Weenink 2017).

\subsubsection{Pitch landmarks}

F0 was collected using Praat's "Get Pitch" function, and smoothed with a bandwidth of $10 \mathrm{~Hz}$. The corrected text grids and F0 tracks were then processed with a Matlab script. Pitch track landmarking was done using a Matlab script that first found F0 extrema located within certain boundaries - for example, the search for F0 peaks in Belgrade falling accents was restricted to no earlier than the acoustic beginning of the word, and no later than the second syllable nucleus. These boundaries were defined differently for Belgrade and Valjevo speakers, due to the dialect-based timing difference. The resulting pitch landmarks were then used to bound where further landmarks could be located.

After pitch landmarking was completed, each trial was verified by hand for reasonable tracking. Several trials had to be excluded due to irreconcilably incorrect pitch tracking, or pitch tracks that did not clearly show minima or maxima. Only F0 trajectories with clear 0 velocity points between the carrier and target words can be used to determine the start and duration of the pitch excursion, as otherwise it is impossible to determine where the upward pitch excursion for the target word begins. F0 minima were more prone to unreliability than pitch maxima due to intonational differences within and between participants. Various intonational patterns completely obscured this minimum, including focus on the carrier word rather than on the target word. Two examples of such tokens from the Belgrade dialect are given in Figure 3; compare the tokens with clear minima in Figure 4.

In the Belgrade dialect, out of a possible 450 trials, 427 had suitable peak marking; out of those 427 trials, 401 also had suitable minima. In the Valjevo dialect, out of a possible 720 trials, 693 had suitable peak marking; out of those 690 trials, 456 also had suitable minima. 


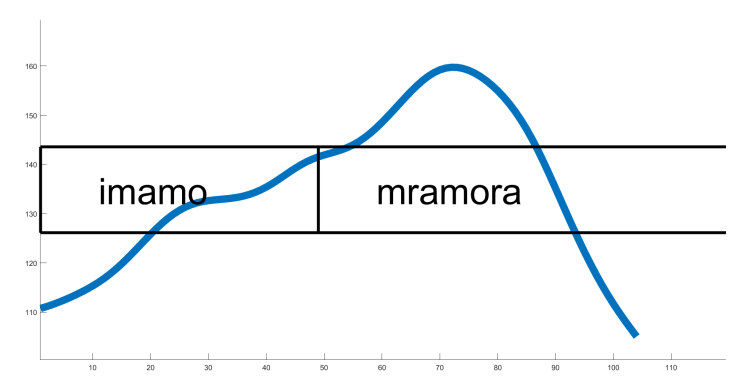

(a) No peak in carrier; smooth rise from beginning until the offset of the falling accent.

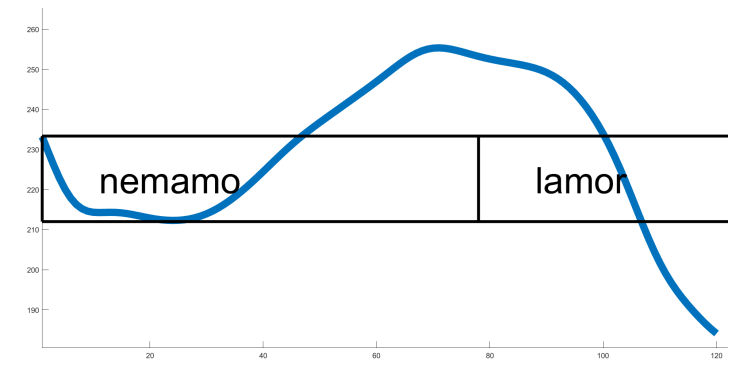

(b) Peaks from carrier and target "coalesced" with plateau near the word boundary.

Figure 3: Examples of F0 shapes that were removed for the analysis of F0 onsets.

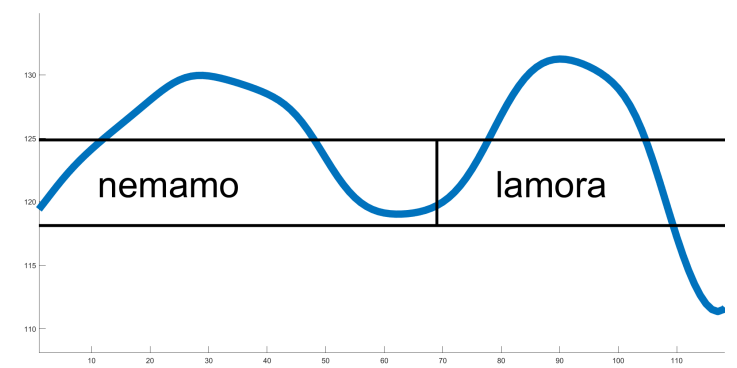

(a) Even peaks from carrier to target, clear minimum in between.

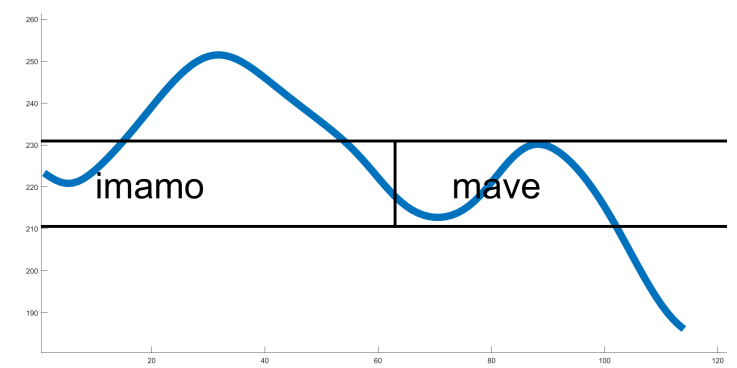

(b) Carrier peak higher than target peak, but still clear minimum in between.

Figure 4: Examples of F0 shapes that allow analysis of F0 onsets.

Some participants had more data deleted than others, but with one exception, remaining data was balanced across syllable onset and accent within participant.

As the absolute F0 peak is less stable and prone to small fluctuations, peak timing was measured using the gestural release rather than the actual target F0 peak. The $\mathrm{H}$ gesture release was marked at the first point after the accentual F0 peak where F0 speed achieved $20 \%$ of the maximum release speed, Similarly, analyses that involve the start of upward F0 movement references the F0 onset, rather than the F0 valley. This was marked at the first point after the F0 valley where F0 speed achieved $20 \%$ of the maximum onset speed. This type of landmarking is typical for Articulatory Phonology trajectories and has been used to landmark pitch gestures as well as segmental gestures (Gao 2008; Karlin 2014; Yi 2014). 


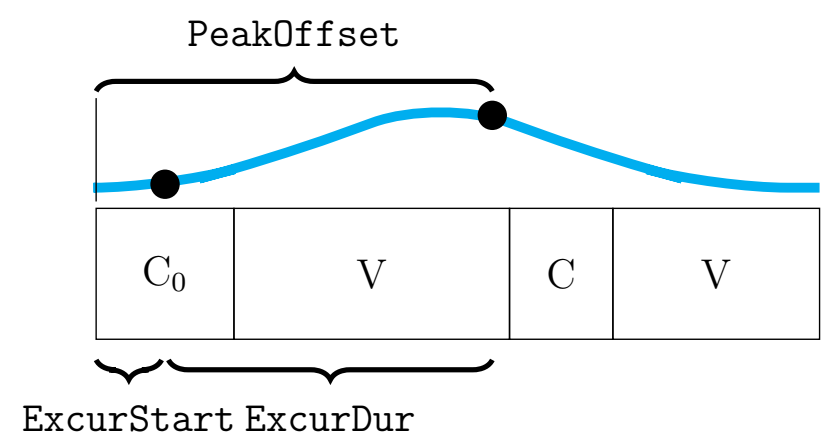

Figure 5: A schema of the dependent variables used in analysis. The blue line is a schematized short falling accent, with black dots to mark the start (leftmost) and peak offset (rightmost) of the pitch excursion.

\subsubsection{Statistical analyses}

Data was analyzed with a linear-mixed effects model in R (R Core Team 2019), using the package lme4 for model building (Bates, Maechler, Bolker, Walker, et al. 2014) and lmerTest to get p values for model components (Kuznetsova, Brockhoff, \& Christensen 2015). Models had fixed effects of syllable onset duration (duration of the varied syllable onset) and length (short vs. long). Dialects are first examined separately, and then together to examine the effect of dialect. Random intercepts were included for participant. Models were built incrementally, and likelihood ratio tests used to compare models; final models include only factors that significantly improved model fit. Post-hoc tests were done using least means squared tests with a Tukey adjustment using the emmeans package (Lenth 2019). Dependent variables are peak offset (timing of accentual peak relative to the beginning of the word), start of pitch excursion (interval between the start of the upward pitch trajectory and the beginning of the word), and the duration of the pitch excursion (interval between peak offset and start of pitch excursion). A schematic of these variables is provided in Figure 5.

\subsection{Results}

\subsubsection{Segmental properties}

As including dialect as a predictor of syllable onset duration did not significantly improve model fit $\left(\chi^{2}(1)=0.93, \mathrm{p}=0.33\right)$, the data for syllable onset duration is pooled. There is a significant effect of syllable onset identity on syllable onset duration. All syllable onsets are 
significantly different from each other $(\mathrm{p}<0.0001$ for all comparisons $): / \mathrm{r} /(45.4 \pm 2.28 \mathrm{~ms})$

$</ \mathrm{l} /(66.8 \pm 2.28 \mathrm{~ms})</ \mathrm{m} /(92.0 \pm 2.28 \mathrm{~ms})</ \mathrm{mr} /(127.6 \pm 2.27 \mathrm{~ms})</ \mathrm{ml} /(137.2$ $\pm 2.28 \mathrm{~ms})$.

\subsubsection{H achievement (peak offset)}

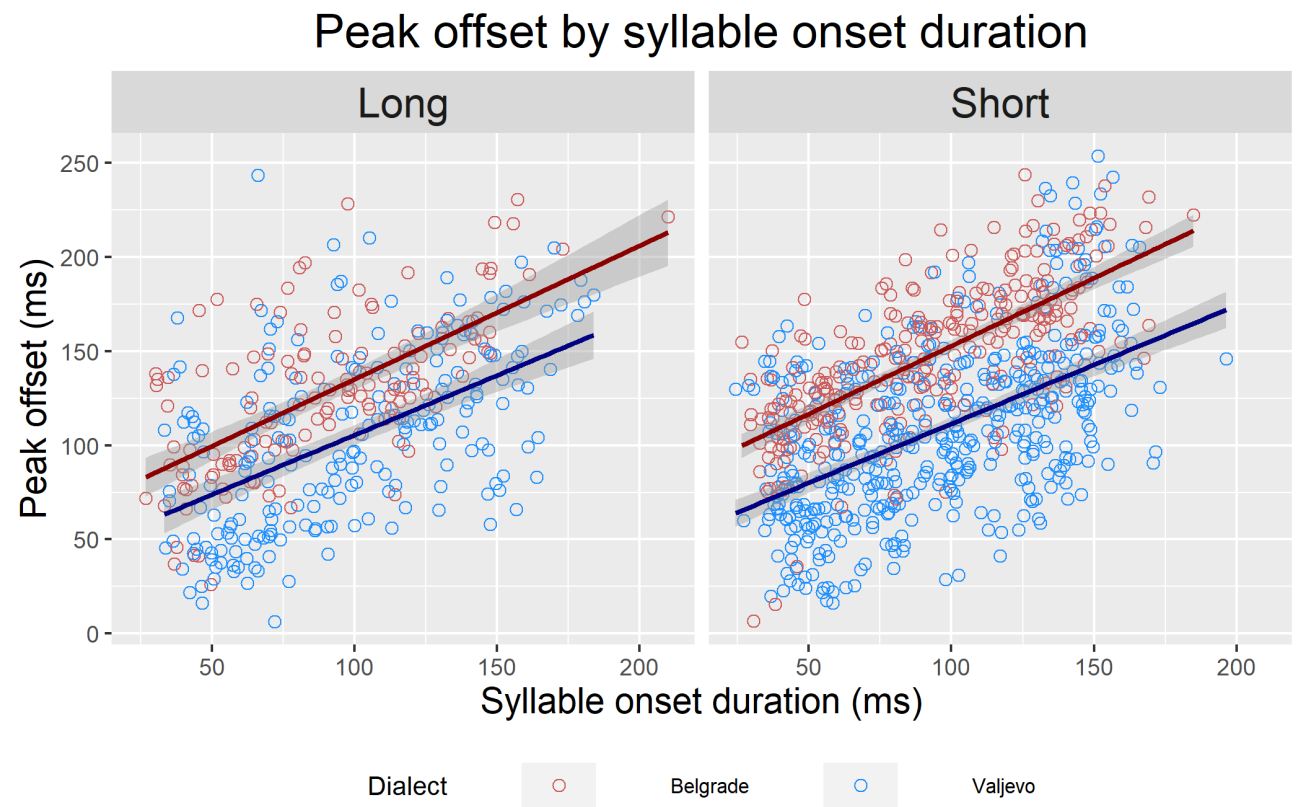

Figure 6: Scatter plots comparing the relationships between varied syllable onset durations and peak offset in falling words (both dialects).

The two dialects have similar patterns for $\mathrm{H}$ achievement; these are illustrated in Figure 6. In the Belgrade dialect, peak offset is affected by the duration of the syllable onset. Syllable onset duration as a single fixed effect significantly improves the model; words with longer syllable onsets have later peak offsets $(\beta=0.72 \mathrm{~ms}, \mathrm{SE}=0.04 \mathrm{~ms})$. The addition of accent also significantly improves the fit of the model; peak offsets occur significantly later in words with short vowels $(147.0 \pm 6.36 \mathrm{~ms})$ than in words with long vowels $(130.0 \pm 6.55 \mathrm{~ms}$, $\mathrm{p}<0.0001)$. The interaction between accent and syllable onset duration is not significant $\left(\chi^{2}(1)=0.13, \mathrm{p}=0.72\right)$, indicating that syllable onset duration affects peak offset timing in both short and long falling accents equally.

Patterns are similar in the Valjevo dialect. The addition of syllable onset duration significantly improves the fit of the model; words with longer syllable onsets have later peak offsets $(\beta=0.66 \mathrm{~ms}, \mathrm{SE}=0.03 \mathrm{~ms})$. The addition of accent also significantly improves 
the fit of the model, where again accentual peaks occur significantly later in short falling words $(109.0 \pm 10.0 \mathrm{~ms})$ than in long falling words $(103.0 \pm 10.1 \mathrm{~ms}, \mathrm{p}=0.01)$. As the difference in both dialects is quite small, it is unlikely that this is under deliberate control. The interaction between accent and syllable onset duration is not significant $\left(\chi^{2}(1)=0.10\right.$, $\mathrm{p}=0.75)$.

In all, both dialects show effects of syllable onset duration on the timing of $\mathrm{H}$ achievement. In a model that includes both dialects, adding dialect as a fixed effect significantly improves the fit of the model; as described previously in the literature, pitch peaks overall occur earlier in the TBU in the Valjevo dialect $(104.0 \pm 8.54 \mathrm{~ms})$ than in the Belgrade dialect (142.0 \pm $10.80 \mathrm{~ms}$ ). Adding the interaction between dialect and syllable onset duration does not significantly improve the model $\left(\chi^{2}(1)=0.92, \mathrm{p}=0.34\right)$, indicating that in both dialects, accentual peaks occur later with increased syllable onset duration. Adding the interaction between dialect and accent does significantly improve the model; as previously noted, there is a smaller difference in peak offset between short and long falling accents in the Valjevo dialect as compared to the Belgrade dialect. The three-way interaction between dialect, accent, and syllable onset duration does not significantly improve the fit of the model $\left(\chi^{2}(1)\right.$ $=0.24, \mathrm{p}=0.63)$. The summary for the final model is provided in Table 2 .

Table 2: Summary of the LME model for peak offset: peakOffset $\sim$ onsetDuration + accent + dialect + accent $:$ dialect $+(1 \mid$ Part $)$. Reference levels: accent $=$ long, dialect $=$ Belgrade

\begin{tabular}{lcccc}
\hline & $\beta$ & $\mathrm{SE}$ & $\mathrm{t}$ value & $p$ value \\
\hline (Intercept) & 67.36 & 10.29 & 6.55 & $<0.0001^{* * *}$ \\
Onset & 0.68 & 0.02 & 31.55 & $<0.0001^{* * *}$ \\
Short & 17.69 & 2.79 & 6.35 & $<0.0001^{* * *}$ \\
Valjevo & -29.94 & 12.88 & -2.32 & $0.04^{*}$ \\
Short:Valjevo & -11.88 & 3.55 & -3.34 & $0.0009^{* * *}$ \\
\hline
\end{tabular}

\subsubsection{Excursion characteristics}

Start of excursion The timing of the start of the pitch excursion patterns differently in each dialect; this is illustrated in Figure 7. In the Belgrade dialect, the addition of syllable onset duration significantly improves the fit of the model; pitch excursions start later in words with longer syllable onsets $(\beta=0.40 \mathrm{~ms}, \mathrm{SE}=0.03 \mathrm{~ms})$. The addition of accent does not significantly improve the fit of the model $\left(\chi^{2}(1)=1.58, \mathrm{p}=0.21\right)$, nor does the interaction between accent and syllable onset duration $\left(\chi^{2}(1)=0.71, \mathrm{p}=0.40\right)$. The effect of syllable onset duration on the start time of the pitch excursion is the same for both long 


\section{Excursion start by syllable onset duration}

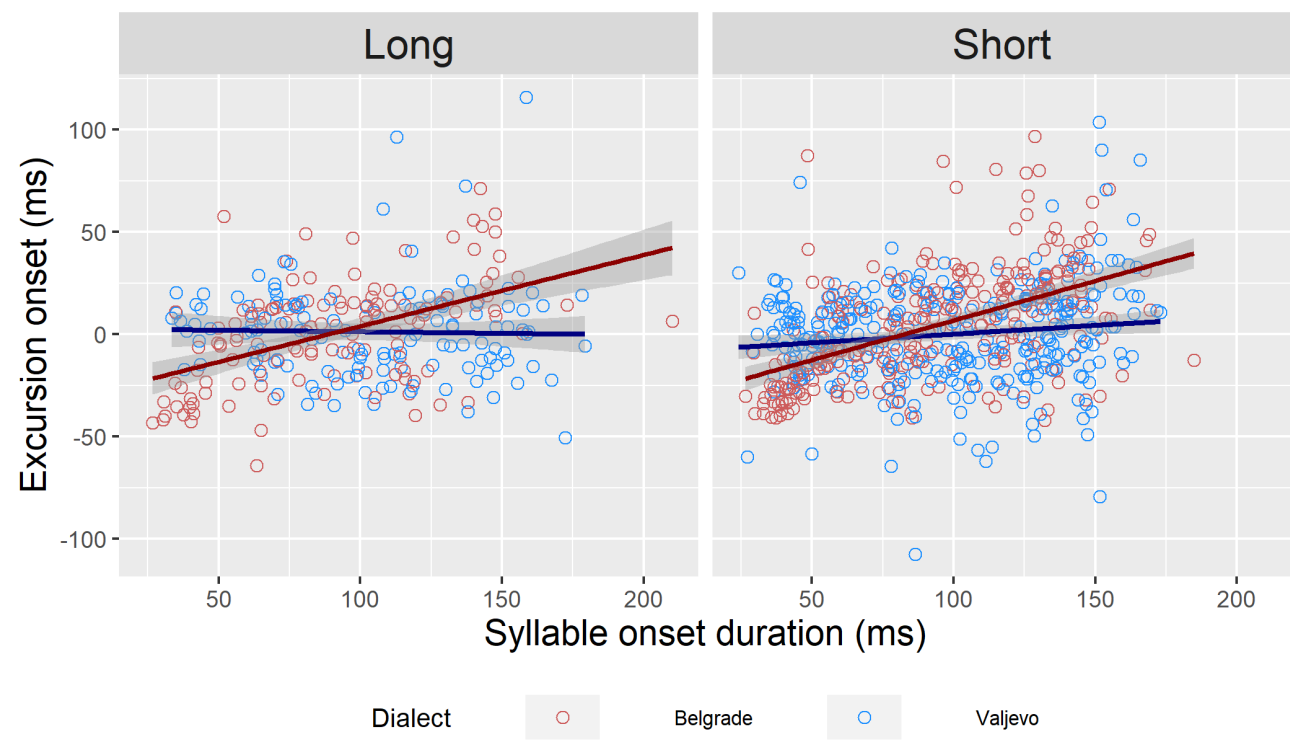

Figure 7: Scatter plots comparing the relationships between varied syllable onset durations and start of the pitch excursion in falling words (both dialects).

and short falling words.

The Valjevo dialect behaves somewhat similarly, though the pitch excursion moves less in response to syllable onsets than in the Belgrade dialect. The addition of syllable onset duration significantly improves the fit of the model in the Valjevo dialect; pitch excursions start slightly later in words with longer syllable onsets $(\beta=0.11 \mathrm{~ms}, \mathrm{SE}=0.03 \mathrm{~ms})$. Adding accent does not significantly improve the fit of the model $\left(\chi^{2}(1)=0.0001, \mathrm{p}=0.99\right)$, nor does the interaction between accent and syllable onset duration $\left(\chi^{2}(1)=2.15, \mathrm{p}=0.14\right)$.

In a model that considers both dialects together, adding syllable onset duration significantly improves model fit. Adding dialect does not improve the model fit $\left(\chi^{2}(1)=0.51, \mathrm{p}\right.$ $=0.48)$. However, adding the interaction between dialect and syllable onset duration does significantly improve model fit; syllable onset duration has less effect on the timing of the start of the pitch excursion in the Valjevo dialect than in the Belgrade dialect $(\beta=-0.28$ $\mathrm{ms}, \mathrm{SE}=0.04 \mathrm{~ms}, \mathrm{p}<0.0001)$. No other factors or their interactions significantly improve the fit of the model. The summary of the full model is provided in Table 3. 
Table 3: Excursion start timing: excurStart $\sim$ onsDur + dialect + dialect:onsDur + (1|Part). Reference levels: accent $=$ long, dialect $=$ Belgrade

\begin{tabular}{lcccc}
\hline & $\beta$ & $\mathrm{SE}$ & $\mathrm{t}$ value & $p$ value \\
\hline (Intercept) & -33.88 & 5.36 & -6.32 & $<0.0001^{* * *}$ \\
Onset & 0.40 & 0.03 & 13.83 & $<0.0001^{* * *}$ \\
Valjevo & 22.79 & 7.07 & 3.23 & $0.003^{* *}$ \\
Onset:Valjevo & -0.28 & 0.04 & -7.22 & $<0.0001^{* * *}$ \\
\hline
\end{tabular}

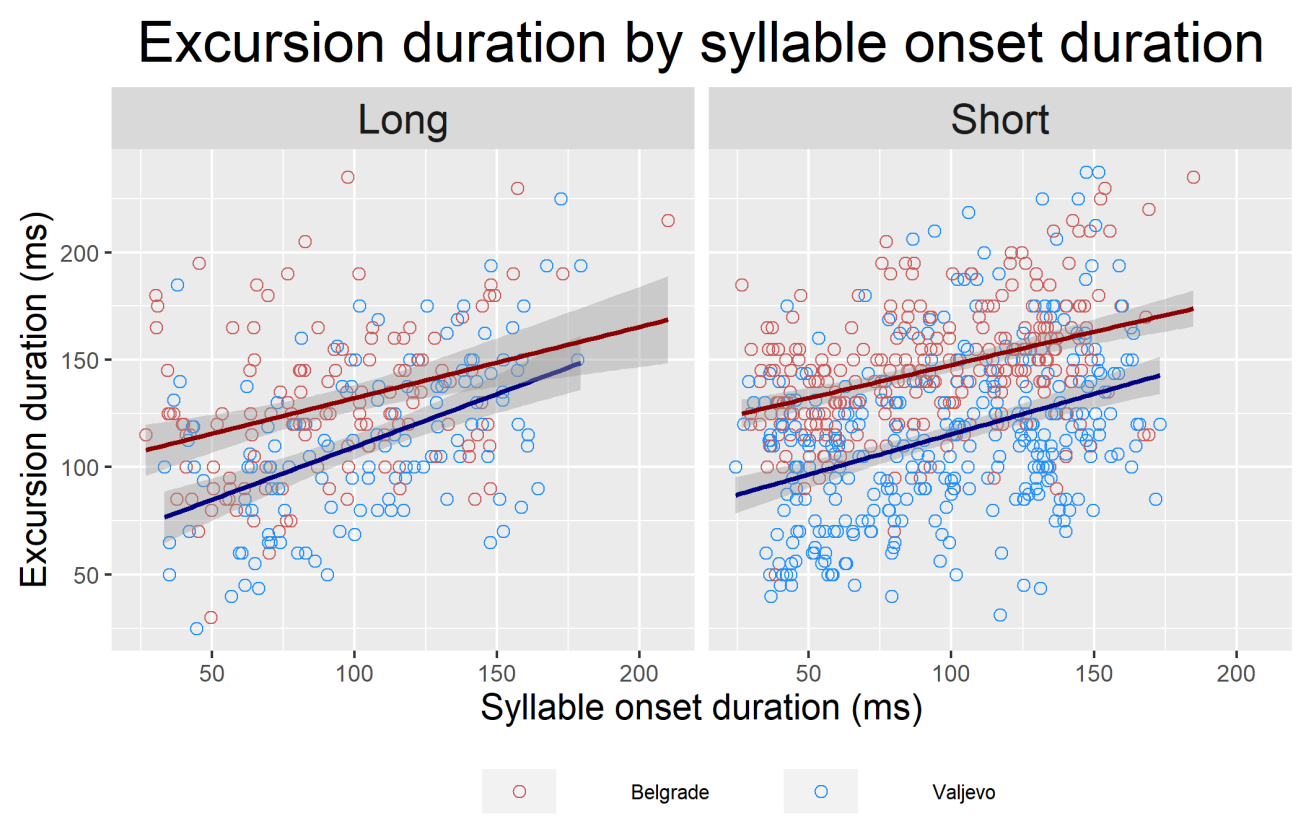

Figure 8: Scatter plots comparing the relationships between varied syllable onset durations and excursion duration in falling words (both dialects).

Excursion duration The patterns for excursion duration in both dialects are illustrated in Figure 8. The duration of the pitch excursion is affected by the syllable onset duration in the Belgrade dialect. Adding syllable onset duration to the model significantly improves the fit; words with longer syllable onsets also have longer pitch excursions $(\beta=0.29 \mathrm{~ms}, \mathrm{SE}=$ $0.04 \mathrm{~ms}$ ). Adding accent as a second fixed effect significantly improves the fit of the model $\left(\chi^{2}(1)=12.87, \mathrm{p}=0.0003\right)$; pitch excursions in short falling words are significantly longer $(147.0 \pm 8.1 \mathrm{~ms})$ than pitch excursions in long falling words $(131.0 \pm 7.9 \mathrm{~ms}, \mathrm{p}<0.0001)$ Thus, accentual peaks occur later in short falling words due to the duration of the pitch 
excursion, rather than the start of the pitch excursion. The interaction between accent and syllable onset duration does not significantly improve the fit $\left(\chi^{2}(1)=0.09, \mathrm{p}=0.77\right)$.

In the Valjevo dialect, syllable onset duration significantly improves the fit of the model; words with longer syllable onsets have longer pitch excursions $(\beta=0.49 \mathrm{~ms}, \mathrm{SE}=0.04 \mathrm{~ms})$. The addition of accent significantly improves the fit of the model; short accents have longer excursions $(114.0 \pm 7.7 \mathrm{~ms})$ than long accents $(114.0 \pm 8.0 \mathrm{~ms})$. The interaction between accent and syllable onset duration does not significantly improve the model fit $\left(\chi^{2}(1)=1.67\right.$, $\mathrm{p}<0.00010 .20$ ); pitch excursions stretch with syllable onset duration equally in both short and long falling accents.

When considering both dialects together, the addition of dialect marginally improves the fit of the model $\left(\chi^{2}(1)=7.37, \mathrm{p}=0.007\right)$; excursions in the Valjevo dialect are shorter than excursions in the Belgrade dialect $(\beta=-46.77 \mathrm{~ms}, \mathrm{SE}=12.03 \mathrm{~ms}, \mathrm{p}=0.0008)$. Both dialects increase the duration of their pitch excursions with longer syllable onsets; however, the addition of the interaction between dialect and syllable onset duration significantly improves the model, where Valjevo pitch excursions increase more with increased syllable onset duration $(\beta=0.21 \mathrm{~ms}, \mathrm{SE}=0.05 \mathrm{~ms}, \mathrm{p}<0.0001)$. The interaction between accent and dialect also significantly improves the model fit; the difference between excursion durations in the long and short accents is smaller in the Valjevo dialect than in the Belgrade dialect $(\beta=-8.73 \mathrm{~ms}, \mathrm{SE}=3.99 \mathrm{~ms} 0.03)$. No other interactions significantly improve the model. The summary of the full model is provided in Table 4.

Table 4: Excursion duration: excurDur $\sim$ onsDur + accent + dialect + dialect:accent + dialect:onset $+(1 \mid$ Part $) . \quad$ Reference levels: accent $=$ long, dialect $=$ Belgrade

\begin{tabular}{lcccc}
\hline & $\beta$ & $\mathrm{SE}$ & $\mathrm{t}$ value & $p$ value \\
\hline (Intercept) & 104.72 & 9.15 & 11.44 & $<0.0001^{* * *}$ \\
Onset & 0.29 & 0.04 & 7.89 & $<0.0001^{* * *}$ \\
Short & 15.50 & 2.85 & 5.43 & $<0.0001^{* * *}$ \\
Valjevo & -46.77 & 12.03 & -3.89 & $0.0008^{* *}$ \\
Short:Valjevo & -8.73 & 3.99 & -2.19 & $0.03^{*}$ \\
Onset:Valjevo & 0.21 & 0.05 & 34.22 & $<0.0001^{* * *}$ \\
\hline
\end{tabular}

\subsection{Interim summary}

This experiment provided a baseline for the behavior of pitch accents in Serbian. In both dialects, $\mathrm{H}$ achievement is later when the lexical $\mathrm{H}$ is associated to a syllable with longer syl- 
lable onset. However, the two dialects achieve this in different ways. In the Belgrade dialect, pitch excursions both start later and get longer with increases in syllable onset duration. In the Valjevo dialect, the pitch excursions start only slightly later with increased syllable onset duration, and the bulk of the peak offset timing comes from stretching the pitch excursion with increased syllable onset duration. As the phonological representation of falling accents is uncontroversial, this indicates that the two dialects have different coordinative schemes for the same phonological relationship. Despite these small differences, however, in both dialects it is true that the timing of the TBU provides timing information to the accentual pitch excursion. As rising accents may differ in phonological representation between the two dialects, we can compare this baseline of how falling accents behave in each dialect to the behavior of rising accents in each two dialect in Experiment 2.

\section{Experiment 2: Rising accents}

In order to probe the association of the $\mathrm{H}$ tone in rising accents in Belgrade and Valjevo Serbian, I examine the effects of syllable onset on the coordination and timing of the rising accent in two rising accent manipulations: first, when only the stressed syllable varies in onset complexity, and second, when only the post-tonic syllable (proposed TBU) varies in onset complexity.

\subsection{Methods}

\subsubsection{Participants}

Participants were recruited according to the same criteria as in Experiment 1. Data was collected from 19 participants (10 Belgrade, 9 Valjevo). Some data had to be excluded due to consistent production errors, either segmental or accentual (three participants) or due to an alternative lexical accent ${ }^{5}$ of the target word omladinu (two speakers). In all, the dataset includes eight (4F, 4M) Belgrade speakers and six (5F, 1M) Valjevo speakers. Four of the Belgrade speakers and three of the Valjevo speakers had previously participated in Experiment 1.

\subsubsection{Target words}

The target words for Experiment 2 were very similar to those used in Experiment 1, but focus solely on short accents. As in Experiment 1, the target words were formed

\footnotetext{
${ }^{5}$ Producing omladinu with a falling accent is linked to older speakers and those from regions other than Belgrade; typically younger speakers, especially those from Belgrade, have a rising accent on this word.
} 


\footnotetext{
${ }^{6}$ The syllabification of òmladinu is unambiguous: first, the principle of maximal syllable onset would encourage a syllabification of /o.mla.di.nu/ rather than /om.la.di.nu/; second, the inclusion of the root mlâd "young" is transparent, which further encourages a syllabification of /o.mla.di.nu/.
}

from three real words, with one syllable onset varied (using /r, l, m, mr, ml/) to make four additional nonce words. The three base words are mrämora 'marble.GEN' (derived words: rämora, lämora, mämora, mlämora); mràvinjak 'anthill' (derived words: ràvinjak, làvinjak, màvinjak, mlàvinjak); and òmladinu 'youth.ACC' (derived words: òradinu, òladinu, òmadinu, òmradinu). ${ }^{6}$ The template mrämora is a short falling accent, which means that the association of the lexical $\mathrm{H}$ to the first syllable is uncontroversial; this provides verification of the effects of the TBU on tone. The template mràvinjak is a short rising accent, where the varied syllable onset is on the stressed syllable and the lexical $\mathrm{H}$ is potentially on the post-tonic syllable. The template òmladinu is also a short rising accent, but the varied syllable onset is on the post-tonic syllable. The òmladinu template is thus the crucial test case; if the lexical $\mathrm{H}$ is associated to the post-tonic syllable, the varied syllable onset will have an effect on the timing of the accentual contour similar to the mrämora template.

\subsubsection{Carrier phrases}

In order to prevent some boredom and make sure the participants were paying attention throughout, two different stimuli frames were used: Da li želite X? 'Did you say X?'. These two stimuli prompted a slightly different initial response (Neću! 'I don't want that!' vs. Nisam! 'I didn't [say that]!'), but the actual carrier sentence, Daj mi $Y$ 'Give me Y', was the same for both stimulus contexts. This context ensured that focus would be put on the target word.

\subsubsection{Task}

As in Experiment 1, participants first heard a context prompt (recorded in advance by a native speaker of Valjevo Serbian that has been living in Belgrade for 20 years) and then read the given response. In order to prevent overlap, rushing, and list intonation, the written response only appeared on the screen after the context prompt ended. The context prompt asked the participant if they wanted or had asked for a certain object; the object in the question was a semantically plausible replacement for the target word, and had the same accent and syllable number as the target words. The same prompts were used for all words in an accentual group, so it was not possible to fully anticipate what the response was, as there are always five possible responses for any given prompt. Two example questions and responses are presented in Figure 9 (where the target word was presented in upper case for the experiment as well, in order to encourage a focused reading). 


$\begin{array}{ll}\text { Context: } & \begin{array}{l}\text { Da li želite drveta? } \\ \text { "Do you want [pieces of] wood?" }\end{array} \\ \text { Response: } & \begin{array}{l}\text { Neću! Daj mi MRAMORA, molim te. } \\ \text { "I don't! Give me [pieces of] MARBLE, please. }\end{array} \\ \text { Context: } & \text { Jeste li rekli 'očevinu'? } \\ \text { "Did you say 'inheritance'?" } \\ \text { Nisam! Daj mi OMLADINU, molim te. }\end{array}$

Figure 9: Example contexts and responses.

There were 15 target phrases total ( $\mathbf{3}$ accent types x $\mathbf{5}$ syllable onsets), with two questions for each target phrase. As in Experiment 1, the order of presentation was fully randomized for every round of the experiment. For this experiment, the 30 prompt questions were put in random order and then split down the middle to make two blocks (thus, two blocks with 15 sentences each). After the two blocks were completed, the 30 sentences were randomized again, instead of repeating the first random order. The sentences were repeated 5 times, for a total of 150 trials.

The experiment was presented using PsychoPy. Participants were recorded in a quiet room, using either a TASCAM DR-100mkII microphone (4 participants, all Belgrade speakers), a Sennheiser noise-canceling headset (4 participants, all Valjevo speakers), or a Shure head-mounted microphone (4 Belgrade speakers, 2 Valjevo speakers).

\subsubsection{Data labeling and analysis}

Data was processed and segmented as in Experiment 1. Single trials were excluded if there were significant disfluencies or segmental or accentual errors (participants that were entirely excluded tended to have at least 30 errors in the experiment; participants who had occasional trials excluded did not exceed 10 errorful trials). Some additional data cleaning was necessary for the analysis of the pitch excursions. Out of a possible 1200 Belgrade tokens, 1,163 had a clear maximum and were retained for an analysis of $\mathrm{H}$ achievement. Of those, 1073 also had clear minima and were retained. Out of a possible 900 tokens in the Valjevo dialect, 882 tokens had a clear maximum, and 846 tokens additionally had clear minima.

Data was analyzed in $\mathrm{R}$ using the same procedures as Experiment 1. Models had fixed effects of TBU syllable onset duration (duration of the onset of the syllable proposed to be 


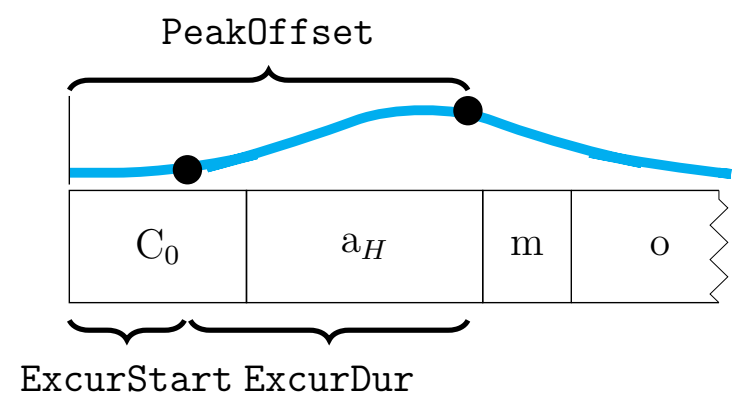

(a) Schematic for falling accent (ämora)

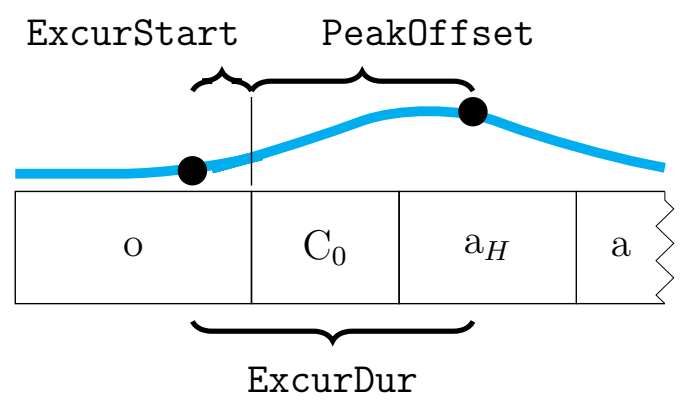

(b) Schematic for rising accent (adinu)

Figure 10: A schema of the dependent variables used in analysis, as marked on falling (a) and rising (b) accents. The blue line is a schematized accent, with black dots to mark the start (leftmost) and peak offset (rightmost) of the pitch excursion.

the TBU in the Inkelas and Zec 1988 analysis), duration of the varied syllable onset (duration of the onset of the syllable with the varied syllable onset), and word template (amora vs. adinu vs. avinjak).

The dependent variables are the same as in Experiment 1. However, for the rising accents the syllable that the timing of the pitch excursion is compared to is the proposed TBU (i.e., the second syllable), rather than the first syllable. This is illustrated in Figure 10.

\subsection{Results}

\subsubsection{Segmental properties}

For the segmental properties (syllable onset duration and nucleus duration) the addition of dialect as a fixed effect does not significantly improve the model $\left(\chi^{2}(1)=0.60, p=0.81\right.$ for syllable onset duration, $\chi^{2}(1)=0.77, \mathrm{p}=0.38$ for rime duration), so the results are pooled and reported together. There is a significant effect of syllable onset identity on syllable onset duration $\left(\chi^{2}(4)=2833.9, \mathrm{p}<0.0001\right), / \mathrm{r} /</ \mathrm{l} /</ \mathrm{m} /</ \mathrm{mr} /</ \mathrm{ml} /($ all $\mathrm{p}<0.0001)$. Adding word template as a second fixed effect significantly improves the model, where adinu syllable onsets are the shortest $(76.0 \pm 2.3 \mathrm{~ms})$, followed by avinjak syllable onsets $(96.7 \pm$ $2.6 \mathrm{~ms})$, with amora syllable onsets the longest $(102.3 \pm 2.6 \mathrm{~ms}$, all $\mathrm{p}<0.0001)$. As the syllable onsets in adinu words belong to an unstressed syllable, it is expected that they would be the shortest; the syllable onsets in the other two templates belong to stressed syllables 


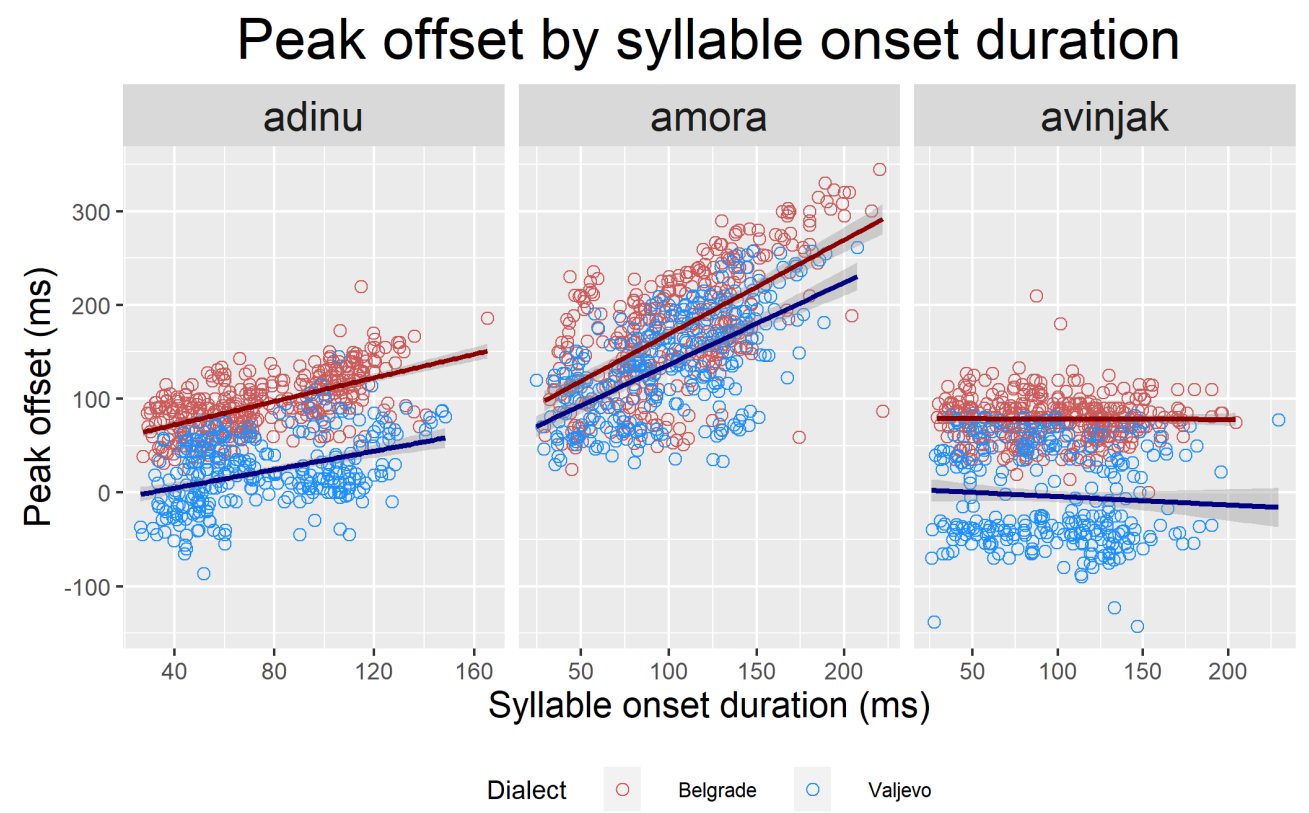

Figure 11: Scatter plots comparing the relationships between TBU syllable onset durations and peak offset in ämora, àvinjak, and adinu words (both dialects).

and are accordingly longer (with estimated means separated $5.6 \mathrm{~ms}$ ).

There is a similar pattern for the duration of the nucleus of the syllable with the varied syllable onset. Word template as a fixed effect significantly improves the fit of the model $\left(\chi^{2}(2)=2021.4, \mathrm{p}<0.0001\right)$; as expected, adinu has the shortest nucleus duration $(79.3 \pm$ $4.4 \mathrm{~ms}$ ), followed by ämora (113.5 $\pm 4.4 \mathrm{~ms})$, and àvinjak words with the longest nuclei (120.2 $\pm 4.4 \mathrm{~ms}$, all $\mathrm{p}<0.0001)$. The addition of syllable onset duration significantly improves the model $\left(\chi^{2}(1)=340.3, \mathrm{p}<0.0001\right)$, where nuclei are slightly shorter when there is a phonetically longer syllable onset $(\beta=-152.9 \mathrm{~ms}, \mathrm{SE}=7.9 \mathrm{~ms}$ for an increase of $1 \mathrm{~s}$ in syllable onset duration).

\subsubsection{H achievement (peak offset)}

The patterns of peak offset timing are illustrated for both dialects in Figure 11. In the Belgrade dialect, the duration of the varied syllable onset as a single predictor significantly improves the fit of the model; accentual peaks occur later when the syllable onset is longer. Adding word template significantly improves the model fit, as does the interaction between template and syllable onset duration. The positive relationship between varied syllable onset 
duration and peak offset exists only for words in the ämora and adinu templates, i.e. words where the onset of the phonologically $\mathrm{H}$ syllable is varied; words in the àvinjak template have a flat-to-negative relationship.

In contrast, when using the duration of the TBU syllable onset, all word templates have a positive relationship between syllable onset duration and peak offset. The duration of TBU syllable onset duration as a single fixed effect significantly improves the fit of the model. This model $($ AIC $=11676.4)$ provides a better fit than the model with the varied syllable onset duration (AIC = 12441.6). Adding word template as a second fixed effect also significantly improves model fit, as does the interaction between TBU syllable onset duration and word template. The effect of syllable onset duration is not different for the adinu and àvinjak templates $(\beta=-0.02 \mathrm{~ms}, \mathrm{SE}=0.15 \mathrm{~ms}), \mathrm{p}=0.91)$, which are the two templates with rising accents. Note that in these models the changes in syllable onset duration for àvinjak are simply trial-to-trial variability in the duration of $/ \mathrm{v} /$, rather than differences due to different segments.

Accentual peaks pattern similarly in the Valjevo dialect. The duration of the varied syllable onset as a single predictor significantly improves the fit of the model; accentual peaks occur later when the syllable onset is longer $(\beta=0.51 \mathrm{~ms}, \mathrm{SE}=0.06 \mathrm{~ms})$. Adding word template significantly improves model fit, as does the interaction between template and syllable onset duration. The difference between the effect of syllable onset duration in adinu and ämora words is statistically significant $(\beta=0.34 \mathrm{~ms}, \mathrm{SE}=0.09 \mathrm{~ms}, \mathrm{p}<0.0001)$, but the relationship between syllable onset duration and peak offset is still positive for both word templates. In contrast, there is a significant difference between adinu and àvinjak words ( $\beta$ $=-0.61 \mathrm{~ms}, \mathrm{SE}=0.08 \mathrm{~ms}, \mathrm{p}<0.0001)$, where àvinjak words have a negative relationship between syllable onset duration and peak offset. This is the same as in the Belgrade dialect.

As in the Belgrade dialect, when using the duration of the TBU syllable onset, all word templates have a positive relationship between syllable onset duration and peak offset. The duration of TBU syllable onset duration significantly improves the fit of the model, and this model (AIC $=9594.6)$ provides a better fit than the model with the varied syllable onset duration ( $\mathrm{AIC}=10,038.6$ ). Adding word template significantly improves model fit, as does the interaction between TBU syllable onset duration and word template. The effect of syllable onset duration is not different for the adinu and àvinjak templates $(\beta=0.03 \mathrm{~ms}$, SE $=0.24 \mathrm{~ms}, \mathrm{p}=0.89)$, as in the Belgrade dialect. However, in this case, the accentual peaks in adinu words occur approximately at the same time as the start of the post-tonic syllable (intercept $\beta=-9.18 \mathrm{~ms}, \mathrm{SE}=12.23 \mathrm{~ms}, \mathrm{p}=0.47$ ); compare the Belgrade dialect where accentual peaks in adinu words occur after the start of the post-tonic syllable (intercept $\beta$ $=54.08 \mathrm{~ms}, \mathrm{SE}=8.40 \mathrm{~ms}, \mathrm{p}<0.0001)$. In Figure 11 it is evident that a good number 
of tokens have accentual peaks preceding the start of the post-tonic syllable, mainly tokens with short onsets $(/ \mathrm{r} /$ and $/ \mathrm{l} / \mathrm{)}$ but also including some with the longer syllable onsets. This indicates that in the Valjevo dialect, the accentual contour is getting timing information from the onset of the post-tonic syllable even when it has been acoustically retracted from that syllable.

Overall, the Belgrade and Valjevo dialects look similar to each other. In a model including both dialects, adding dialect as a fixed effect significantly improves the fit of the model; Valjevo peaks occur earlier relative to the start of the syllable $(\beta=-62.92 \mathrm{~ms}, \mathrm{SE}=12.76 \mathrm{~ms}$, $\mathrm{p}=0.0002$ ), which aligns with the data from Experiment 1, as well as previous descriptions of the Valjevo dialect. Adding the interaction between dialect and syllable onset duration also significantly improves the model; syllable onset duration has a great effect on peak offset in the Valjevo dialect $(\beta=0.25 \mathrm{~ms}, \mathrm{SE}=0.04 \mathrm{~ms}, \mathrm{p}<0.0001)$. The interaction between dialect and template also significantly improves the model. Although in both dialects the peaks in falling accents occur later than peaks in rising accents (due to the increased duration of stressed syllables, which falling accentual peaks occur on), in the Valjevo dialect there is a greater difference between adinu and ämora words $(\beta=42.34 \mathrm{~ms}, \mathrm{SE}=9.40 \mathrm{~ms}, \mathrm{p}<$ 0.0001). This is likely due to the fact that rising accents are sometimes fully retracted off the H-bearing syllable, but falling accentual peaks still occur within the word, meaning that they cannot be retracted to before the first syllable of the word. The three-way interaction between onset duration, template, and dialect does not improve model fit (for full model summary, see Table 5).

Table 5: Summary of the LME model for peak offset, using the duration of the TBU syllable onset. Model: peakOffset $\sim$ onsDur + template + onsDur:template + dialect + dialect:onsDur + dialect:template $+(\mid$ Part $)$. Reference Levels: template $=$ adinu , dialect $=$ Belgrade

\begin{tabular}{lcccc}
\hline & $\beta$ & $\mathrm{SE}$ & $\mathrm{t}$ value & $p$ value \\
\hline (Intercept) & 53.79 & 9.16 & 5.87 & $<0.0001^{* * *}$ \\
Onset & 0.54 & 0.05 & 11.79 & $<0.0001^{* * *}$ \\
ämora & 27.47 & 4.94 & 5.56 & $<0.0001^{* * *}$ \\
àvinjak & -3.39 & 7.57 & -0.45 & 0.65 \\
Valjevo & -62.54 & 13.46 & -4.65 & $0.0002^{* * *}$ \\
Onset:ämora & 0.34 & 0.05 & 6.83 & $<0.0001^{* * *}$ \\
Onset:àvinjak & 0.002 & 0.13 & 0.01 & 0.99 \\
Onset:Valjevo & -0.13 & 0.05 & -2.66 & $0.008^{* *}$ \\
ämora :Valjevo & 42.34 & 3.62 & 11.688 & $<0.0001^{* * *}$ \\
àvinjak :Valjevo & -13.23 & 3.60 & -3.67 & $0.0002^{* * *}$ \\
\hline
\end{tabular}




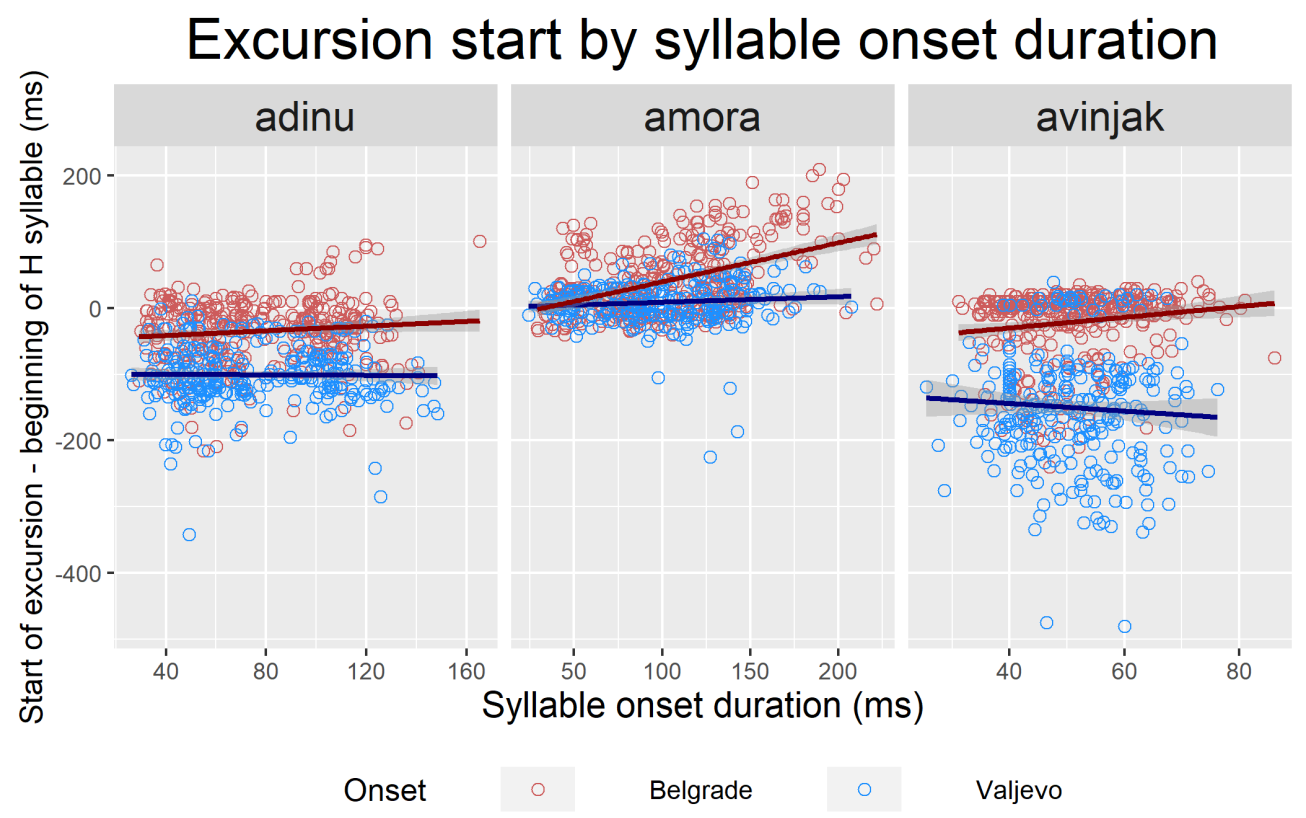

Figure 12: Scatter plots comparing the relationships between varied syllable onset durations and peak offset in ämora, àvinjak, and adinu words (both dialects).

\subsubsection{Excursion characteristics}

For the excursion characteristics, I will focus on the duration of the TBU syllable onset, as it provides a better prediction of the data than the manipulated syllable onset.

Excursion start The timing of the start of the pitch excursion in both dialects is illustrated in Figure 12. In the Belgrade dialect, the addition of word template significantly improves the fit of the model. Pitch excursions in words in the adinu template start the earliest $(-35.3 \pm 9.70 \mathrm{~ms})$ and are similar but significantly different $(\mathrm{p}=0.0004)$ from excursions in words in the àvinjak template $(-22.3 \pm 9.70 \mathrm{~ms})$. Pitch excursions in the ämora template start the latest ( $42.6 \pm 9.7 \mathrm{~ms}, \mathrm{p}<0.0001$ for both comparisons). The addition of syllable onset duration also significantly improves the fit of the model; pitch excursions start later in words with longer syllable onsets $(\beta=0.43 \mathrm{~ms}, \mathrm{SE}=0.05 \mathrm{~ms})$. There is also a significant interaction between template and syllable onset duration. Rising accent excursions do not change when they start based on syllable onset duration (onset duration $\beta=0.12 \mathrm{~ms}$, SE $=0.08 \mathrm{~ms}, \mathrm{p}=0.14$; no difference in effect of onset duration between adinu and àvinjak words, $\beta=0.47 \mathrm{~ms}, \mathrm{SE}=0.27 \mathrm{~ms}, \mathrm{p}=0.07)$. In contrast, falling pitch accents start later 
in words with longer syllable onsets $(\beta=0.45 \mathrm{~ms}, \mathrm{SE}=0.10 \mathrm{~ms}, \mathrm{p}<0.0001)$.

The patterns differ in the Valjevo dialect. The addition of word template significantly improves the fit of the model. Pitch excursions start the earliest in rising words; for the adinu template, pitch excursions start $100.81 \pm 9.89 \mathrm{~ms}$ before the start of the TBU syllable, and in the àvinjak template $150.39 \pm 9.90 \mathrm{~ms}$ before the start of the TBU syllable. Pitch excursions in the ämora template start approximately concurrently with the start of the TBU $(7.24 \pm 9.95 \mathrm{~ms})$. All words are significantly different from each other $(\mathrm{p}<0.0001$ for all comparisons). Unlike in the Belgrade dialect, the addition of onset duration does not significantly improve the fit of the model $\left(\chi^{2}(1)=2.88, \mathrm{p}=0.09\right)$, nor does the interaction between template and syllable onset duration $\left(\chi^{2}(2)=1.27, \mathrm{p}=0.53\right)$. The timing of the start of the pitch excursion is not dependent on the duration of the syllable onset in the Valjevo dialect.

For models considering both dialects, the addition of dialect significantly improves the fit of the model. The interaction between dialect and syllable onset duration also significantly improves the model fit, as does the interaction between dialect and template. Although overall pitch excursions start earlier in the Valjevo dialect than in the Belgrade dialect, the effect of dialect is larger for rising accent words (where accentual peaks are retracted from the second syllable in the Valjevo dialect) than for falling accent words (where accentual peaks still occur in the stressed syllable in both dialect). The three-way interaction between dialect, template, and syllable onset duration also significantly improves model fit. As suggested by the individual dialect models, syllable onset duration affects the timing of the start of the excursion in ämora words but not the two rising accent words in the Belgrade dialect; this differs from the Valjevo dialect where syllable onset duration does not affect the start of the pitch excursion in any template. These results parallel those from Experiment 1 . The full model summary is available in Table 6 .

Excursion duration The patterns of excursion duration for both dialects are illustrated in Figure 13. In the Belgrade dialect, the addition of template significantly improves the fit of the model. Words in the adinu $(131.0 \pm 9.17 \mathrm{~ms})$ and the ämora $(130.0 \pm 9.16 \mathrm{~ms})$ templates have the longest pitch excursions (no significant difference, $\mathrm{p}=0.94$ ); words in the àvinjak template have the shortest excursions $(100.0 \pm 9.16 \mathrm{~ms})$. The addition of syllable onset duration also significantly improves the fit of the model; words with a longer syllable onset have longer pitch excursions $(\beta=0.32 \mathrm{~ms}, \mathrm{SE}=0.04 \mathrm{~ms})$. The interaction between template and onset duration is also significant; syllable onset duration affects excursion duration equally in adinu and ämora words $(\mathrm{p}=0.24)$, but differently in àvinjak words $(\beta$ $=-0.64 \mathrm{~ms}, \mathrm{SE}=0.23 \mathrm{~ms} 0.006)$. It is unclear why àvinjak excursions are different than 
Table 6: Full LME model for the start of pitch excursion, with the duration of the TBU syllable onset. Model: excurStart onsDur*template*dialect + (|Part). Reference Levels: template $=$ adinu , dialect $=$ Belgrade

\begin{tabular}{lcccc}
\hline & $\beta$ & $\mathrm{SE}$ & $\mathrm{t}$ value & $p$ value \\
\hline Intercept) & -44.70 & 11.15 & -4.00 & $0.0002^{* * *}$ \\
Onset & 0.12 & 0.09 & 1.29 & 0.20 \\
ämora & 28.51 & 10.48 & 2.72 & $0.007^{* *}$ \\
àvinjak & -7.89 & 16.43 & -0.48 & 0.63 \\
Valjevo & -62.77 & 16.64 & -3.77 & $0.0005^{* * *}$ \\
Onset:ämora & 0.45 & 0.11 & 3.96 & $<0.0001^{* * *}$ \\
Onset:àvinjak & 0.47 & 0.29 & 1.59 & 0.11 \\
Onset:Valjevo & -0.03 & 0.14 & -0.25 & 0.81 \\
ämora : Valjevo & 70.42 & 15.61 & 4.51 & $<0.0001^{* * *}$ \\
àvinjak : Valjevo & -22.60 & 24.73 & -0.91 & 0.36 \\
Onset:ämora :Valjevo & -0.38 & 0.17 & -2.21 & $0.03^{*}$ \\
Onset:àvinjak :Valjevo & -0.80 & 0.45 & -1.78 & 0.808 \\
\hline
\end{tabular}

adinu and ämora excursions, but one possibility is that differences in the duration of the TBU syllable onset are simply from trial-to-trial differences in the production of $/ \mathrm{v} /$, rather than a gross change from $/ \mathrm{r} /$ to $/ \mathrm{ml} /$.

The Valjevo dialect patterns slightly differently than Belgrade in the duration of their pitch excursions. The addition of template significantly improves the fit of the model. Unlike in the Belgrade dialect, however, words in the adinu (123.0 $\pm 17.50 \mathrm{~ms})$ and the ämora (126.0 $\pm 17.50 \mathrm{~ms}$ ) have the shortest pitch excursions (no significant difference between the two, $\mathrm{p}=0.80$ ), while àvinjak words have the longest pitch excursions (146.0 $\pm 17.50 \mathrm{~ms})$. The addition of syllable onset duration significantly improves the fit of the model; words with longer syllable onsets have longer pitch excursions $(\beta=0.47 \mathrm{~ms}, \mathrm{SE}=0.07 \mathrm{~ms})$. The interaction between template and syllable onset duration is not significant $\left(\chi^{2}(2)=2.98, \mathrm{p}\right.$ $=0.23)$, indicating that both accents have this effect.

In a model that considers both dialects together, dialect as a fixed effect does not significantly improve the fit of the model $\left(\chi^{2}(1)=0.59, \mathrm{p}=0.44\right)$, suggesting that overall pitch excursions are the same duration in both dialects. However, there is a significant interaction between dialect and syllable onset duration. Adding the interaction between dialect and group also significantly improves the fit of the model, as does the three-way interaction between syllable onset duration, template, and dialect. This comes mainly from an increased effect of syllable onset duration in ämora $(\beta=0.34 \mathrm{~ms}, \mathrm{SE}=0.16 \mathrm{~ms}, \mathrm{p}=0.03)$ and àvinjak $(\beta=0.92 \mathrm{~ms}, \mathrm{SE}=0.42 \mathrm{~ms}, \mathrm{p}=0.03)$ words in the Valjevo dialect; there is no difference 


\section{Excursion duration by syllable onset duration}

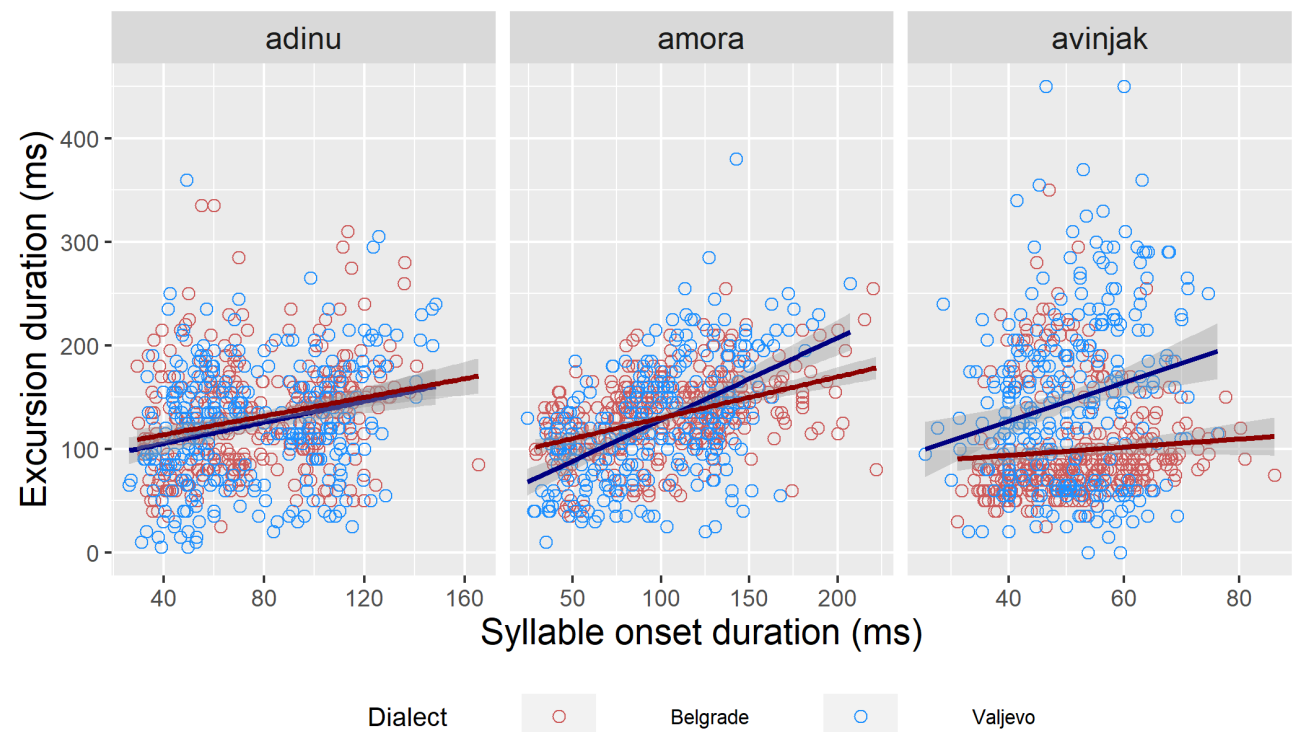

Figure 13: Scatter plots comparing the relationships between varied syllable onset durations and peak offset in ämora, àvinjak, and adinu words (both dialects).

in the effect of syllable onset duration in adinu words between the Valjevo and Belgrade dialects $(\beta=-0.08 \mathrm{~ms}, \mathrm{SE}=0.13 \mathrm{~ms}, \mathrm{p}=0.52)$. Rising accents in both the Belgrade and the Valjevo dialect receive timing information from the TBU, even though in the Valjevo dialect the peaks occur much earlier. A summary of the full model is provided in Table 7 .

Taken together, these results suggest that Valjevo accentual peaks occur earlier not via shorter pitch excursions, but rather through starting the pitch excursions earlier relative to the TBU. However, in both dialects, the pitch accents receive timing information (durational in the case of Valjevo; both duration and initial timing in Belgrade) from the TBU proposed in Inkelas and Zec (1988). This indicates that Valjevo accentual peaks are merely phonetically retracted, and that rising accents have not undergone a phonological shift to the tonic syllable. 
Table 7: Full LME model for the duration of the pitch excursion, with the duration of the TBU syllable onset (onsdur). Model: excurDur $\sim$ onsDur*template*dialect + (|Part) Reference Levels: template $=$ adinu , dialect $=$ Belgrade

\begin{tabular}{lcccc}
\hline & $\beta$ & $\mathrm{SE}$ & $\mathrm{t}$ value & $p$ value \\
\hline (Intercept) & 100.22 & 12.505 & 8.02 & $<0.0001^{* * *}$ \\
Onset & 0.41 & 0.09 & 4.60 & $<0.0001^{* * *}$ \\
ämora & -0.79 & 9.87 & -0.08 & 0.94 \\
àvinjak & 11.70 & 15.49 & 0.76 & 0.45 \\
Valjevo & -1.48 & 18.78 & -0.08 & 0.94 \\
Onset:ämora & -0.11 & 0.11 & -1.00 & 0.32 \\
Onset:àvinjak & -0.64 & 0.28 & -2.30 & $0.02^{*}$ \\
Onset:Valjevo & -0.08 & 0.13 & -0.64 & 0.52 \\
ämora :Valjevo & -26.00 & 14.71 & -1.77 & 0.08 \\
àvinjak :Valjevo & 5.21 & 23.31 & 0.22 & 0.82 \\
Onset:ämora :Valjevo & 0.34 & 0.16 & 2.14 & $0.03^{*}$ \\
Onset:àvinjak :Valjevo & 0.92 & 0.42 & 2.17 & $0.03^{*}$ \\
\hline
\end{tabular}

\section{Discussion}

\subsection{Summary}

The results from these two experiments are both consistent with each other and the Inkelas and Zec (1988) account of pitch accents for both the Belgrade and Valjevo dialects. In Experiment 1, I showed that the timing of accentual peaks is influenced by the phonetic characteristics of the TBU in both dialects; in this case, the duration of the syllable onset was positively correlated with the timing of the peak offset. Although accentual peaks occur earlier in the Valjevo dialect, both dialects had this positive relationship. However, the two dialects achieved this timing in different ways. In the Belgrade dialect, the pitch excursion both shifted rightward and increased in duration as syllable onset duration increased; in the Valjevo dialect, the start of pitch excursions were far more consistent across syllable onset duration, and the duration of the excursion changed more. Thus, although the segmental characteristics of the TBU provide timing information for pitch excursions in both dialects, the precise implementation of that timing information differs across dialects.

In Experiment 2, I compared the behavior of rising accents to falling accents in both dialects. The falling accents confirmed the findings from Experiment 1; peak timing is influenced by TBU characteristics in both dialects, but that timing is achieved through different timing strategies in each dialect. The timing of rising accent peaks was better 
predicted by characteristics of the post-tonic syllable, rather than the tonic syllable; when comparing peak timing to the phonetic characteristics of the post-tonic syllable, rising accents behaved similarly to falling accents. This supports the Inkelas and Zec (1988) model of Serbian rising accents, where stress is one syllable to the left of a lexical $\mathrm{H}$ in rising accent words; if pitch accents get timing information from their TBU, then rising accents must be associated to the post-tonic syllable in Serbian. Furthermore, this data rules out the Smiljanić (2002) proposal, where the rising accent is an $\mathrm{L}^{*}+\mathrm{H}$ contour associated to the stressed syllable; this representation predicts that the peak offset will occur after a set interval of time from the stressed nucleus, regardless of the duration of the second syllable onset.

Critically, this was true for rising accents in both dialects, even though rising accent peaks in the Valjevo dialect were retracted, in some cases fully into the tonic syllable. Note that it is likely that "true" peaks in fact occurred earlier than what was documented in this study, as peak offset timing used the $20 \%$ velocity threshold for consistency, which places peak offset timing slightly later than either gestural target achievement or gestural peak. Thus, the Belgrade and Valjevo dialects share the abstract aspects of their phonology, but do not share phonetic realization.

\subsection{Implications}

The phonetic realization of Valjevo rising pitch accents is not predicted by either autosegmental or current gestural theories of tone. Crucially, however, gestural theories of tone representation require a relatively small alteration to predict the data presented here, while autosegmental theories would have to fully rework the definition of a TBU. In autosegmental theory, there is some assumption of acoustic simultaneity (Sagey 1986) between phonologically associated elements. Thus, there is a bit of circular reasoning when determining phonological alignment from phonetics: if a pitch target acoustically occurs during some posited TBU, then its tone must be associated to that TBU; conversely, if a tone is phonologically associated to some TBU, it is predicted that the pitch target will occur sometime during that TBU in the acoustics. It would thus require quite a lot of additional machinery for a pitch accent to be reasonably posited to be associated to the post-tonic syllable if it is phonetically realized entirely in the tonic syllable (i.e., both the beginning and the end of the pitch movement are in the tonic syllable).

In contrast, the Articulatory Phonology model gives priority to articulatory relationships, and articulatory coordination does not necessarily result in acoustic simultaneity. For example, complex codas are anti-phase coordinated with each other (Marin \& Pouplier 2010), but 
the acoustic output is roughly linear and sequential. Similarly, coordination between a tone gesture and segmental gestures need not necessarily result in acoustic simultaneity; in order to predict Valjevo rising accents, it is only necessary to expand the Articulatory Phonology model of lexical tone from exclusively c-center to all modes of coordination allowed to segmental gestures. Further evidence against the c-center hypothesis for tone comes from the differences in Belgrade and Valjevo falling accents. It is impossible for the same c-center coordinative structure to produce the two alignment strategies exhibited by the two dialects: the Belgrade dialect achieves peak alignment by changing both the timing of the start of the pitch excursion as well as the duration of the pitch excursion; the Valjevo dialect mainly utilizes the duration of the pitch excursion.

We can conceptualize of a TBU as a coordinative structure between a tone gesture and some segmental gestures, where the existence of a coordinative relationship plays the role of phonological association and the precise parameters determine the output phonetics. This coordinative structure allows the exchange of timing information between gestures, as shown in these two studies, where pitch gestures shift and stretch in accordance with the segmental gestures. This relationship need not be unidirectional; many previous studies have shown that pitch contours can influence segmental timing, e.g. the duration of rising vs. falling tones ( Yu 2010) or even the insertion of segmental material in Italian (Grice, Savino, \& Roettger 2018) or Berber (Ridouane \& Cooper-Leavitt 2019). It is not possible to express this conditioned variance with a range of stiffness values specified for a gesture, analogous to a window of $\mathrm{F} 0$ values for a tone target, or a window of constriction degree or location for an oral gesture: these ranges of target values are typically meant to express unconditioned variability in the production of a gesture. The difference here, of course, is that tone gestures are stretching in accordance with the gestures they are coordinated with. To capture target timing (peak offset in this study), we can either specify that gestures have target coordination as well as onset coordination, which has been suggested to be an important factor in timing both in the tone domain and the segmental domain (Shaw \& Chen 2019; Turk \& Shattuck-Hufnagel 2020); alternatively, tone gestures can have some sort of "base" stiffness which provides a degree of timing, but is then influenced by the gestures it is coordinated with. In either case, there must be some language-specific optimization of balancing the temporal demands between pitch and segmental movements. In some languages, pitch takes precedence and forces segments to be longer; in others, segmental gestures take precedence and tones will truncate or flatten. These studies do not provide definitive evidence for either of these proposals and as such the question is left for future work. 


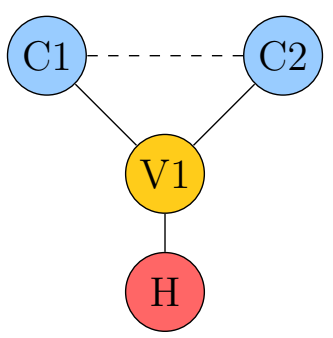

(a) Proposed representation for $/ \mathrm{mra} /$ syllable with a falling accent in Belgrade Serbian.

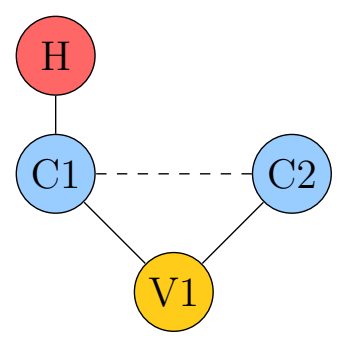

(b) Proposed representation for $/ \mathrm{mra} /$ syllable with a falling accent in Valjevo Serbian.

Figure 14: Model of tonal representation for Belgrade and Valjevo falling accents. The altered c-center structure in the Belgrade dialect produces the bidirectional displacement of the consonant gestures away from the tone gesture. In contrast, the Valjevo tone gesture is coordinated with the first onset consonant only and thus the onset of the tone gesture does not shift with additional consonants.

\subsection{Modeling Serbian tones}

We can now build coordinative models for both the Belgrade and the Valjevo dialects. In the Belgrade falling accent, the $\mathrm{H}$ gesture must be coordinated such the start of the pitch excursion shifts rightward as the syllable onset grows longer. This is simply generated by a c-center structure, though with the tone gesture being coordinated to the c-center, rather than being one of the gestures used to calculate the c-center, as the rightward shift is only approximately $50 \%$ of the duration of the syllable onset. With tone as a centering gesture, the syllable onset consonants would displace away from the onset of the $\mathrm{H}$ gesture in both directions, producing only a partial shift to the right of the acoustic start of the word. The timing of the gestural onset of the $\mathrm{H}$ gesture is affected by the c-center structure, just as the vowel gesture would be affected. This configuration is illustrated in Figure 14.

In contrast, the falling accent in the Valjevo dialect displays timing patterns that are most simply generated by an in-phase coordinative relationship between the $\mathrm{H}$ gesture and the first consonant gesture of the syllable onset. This representation is illustrated in Figure 14b. It is important to note that these models, the entire gestural "constellation" that makes up the distributional TBU informs the timing of the tone gesture, not just the gesture(s) that the tone gesture is immediately coupled to. The data from the Valjevo dialect provides the most compelling evidence: the $\mathrm{H}$ gesture is in-phase coordinated with the first consonant gesture of the syllable onset, but still increases in duration when moving from $/ \mathrm{m} /$ to $/ \mathrm{mr} /$ to $/ \mathrm{ml} /$, which indicates that the second consonant gesture provides timing information to 
the tone gesture despite not being directly coordinated with it.

Finally, an additional model configuration is necessary for the rising accent in Valjevo Serbian, which takes advantage of an additional point of coordination as offered by Gafos (2002). The $\mathrm{H}$ gesture in Valjevo rising accents receives timing information from the posttonic syllable, which indicates that it is coordinated in some way to the segmental gestures of the second syllable. However, unlike falling accents in either dialect, the tone gesture must start well in advance of the post-tonic syllable, meaning that its onset cannot be coordinated to a gesture from the post-tonic syllable. A coordinative relationship between the target of the $\mathrm{H}$ gesture and the c-center of the post-tonic syllable produces the desired phonological association and early alignment. This also produces the later peak achievement as syllable onsets get longer, similarly to how Belgrade tone gestures in falling accents start later with longer onset consonants: the c-center moves later as the syllable onset gets longer, but not by the entire duration of the onset consonants. This structure is modeled in Figure 15.

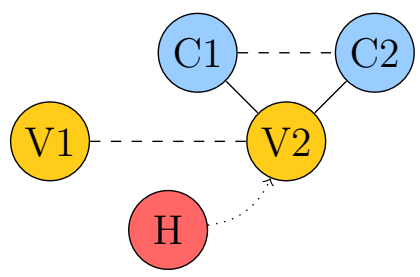

(a) Proposed representation for rising accent on /'o.mla $/$ / sequence in Valjevo Serbian.

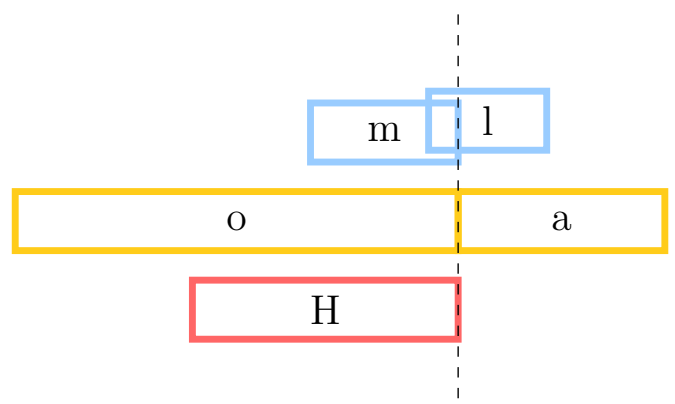

(b) Gestural score that corresponds to (b): rising accent on /'o.mla ${ }_{H} /$ sequence in Valjevo Serbian. Left edge indicates gestural onset; right edge indicates gestural release. Ccenter marked, using the definition provided in Browman and Goldstein 1988.

Figure 15: Model of tonal representation for Valjevo Serbian rising accent, showing both the stressed and post-stress (H-bearing) syllable. The bending dotted line denotes that the gestural target of the $\mathrm{H}$ gesture is coordinated with the c-center of the next syllable.

\section{Conclusion}

The timing patterns of lexical pitch accents in the Belgrade and Valjevo dialects of Serbian indicate that an articulatory conceptualization of the TBU better predicts existing tone data than autosegmental theories. However, Articulatory Phonology models of lexical tone must be updated; the c-center hypothesis for tone is inadequate to describe existing patterns in 
lexical tone languages. Allowing coordination with the same gestural landmarks as proposed for segmental gestures both unifies the treatment of segmental vs. pitch gestures and predicts a greater range of tone patterns that may be found across languages, including those observed in Valjevo Serbian. This highlights the need for more cross-linguistic work in tone under an Articulatory Phonology lens.

\section{References}

Arvaniti, A., Ladd, D. R., \& Mennen, I. (1998). Stability of tonal alignment: the case of Greek prenuclear accents. Journal of Phonetics, 26(1), 3-25.

Arvaniti, A., Ladd, D. R., \& Mennen, I. (2006). Phonetic effects of focus and "tonal crowding" in intonation: Evidence from Greek polar questions. Speech Communication, 48(6), 667-696.

Bates, D., Maechler, M., Bolker, B., Walker, S., et al. (2014). lme4: Linear mixed-effects models using Eigen and s4. R package version, 1(7), 1-23.

Boersma, P., \& Weenink, D. (2017). Praat: doing phonetics by computer. http://www.fon .hum.uva.nl/praat/.

Browman, C. P., \& Goldstein, L. (1988). Some notes on syllable structure in articulatory phonology. Phonetica, 45(2-4), 140-155.

Browman, C. P., \& Goldstein, L. (1990). Gestural specification using dynamically-defined articulatory structures. Status Report on Speech Research, 95-110.

Browman, C. P., \& Goldstein, L. (1992). Articulatory phonology: An overview. Phonetica, $49(3-4), 155-180$.

Browman, C. P., \& Goldstein, L. M. (1986). Towards an articulatory phonology. Phonology, 3, 219-252.

Bruce, G. (1977). Swedish word accents in sentence perspective (Vol. 12). Lund University. DiCanio, C., Amith, J., \& García, R. C. (2014). The phonetics of moraic alignment in Yoloxóchitl Mixtec. In Proceedings of the 4 th interntional symposium on tonal aspects of languages (pp. 203-210).

Fuchs, S., Perrier, P., \& Hartinger, M. (2011). A critical evaluation of gestural stiffness estimations in speech production based on a linear second-order model. Journal of Speech, Language, and Hearing Research, 54(4), 1067-1076.

Gafos, A. I. (2002). A grammar of gestural coordination. Natural Language \& Linguistic Theory, 20(2), 269-337.

Gao, M. (2008). Mandarin tones: An articulatory phonology account (Unpublished doctoral dissertation). Yale University. 
Geissler, C. (2019). Tonal and laryngeal contrasts in Diaspora Tibetan. In S. Calhoun, P. Escudero, M. Tabain, \& P. Warren (Eds.), Proceedings of the XVIIIth International Congress of Phonetic Sciences, Melbourne, Australia (pp. 2421-2424). Canberra, Australia.

Goldstein, L., Chitoran, I., \& Selkirk, E. (2007). Syllable structure as coupled oscillator modes: evidence from Georgian vs. Tashlhiyt Berber. In Proceedings of the XVIth International Congress of Phonetic Sciences (pp. 241-244).

Grice, M., Savino, M., \& Roettger, T. B. (2018). Word final schwa is driven by intonationthe case of bari italian. The Journal of the Acoustical Society of America, 143(4), 24742486.

Hyman, L. M. (1988). Syllable structure constraints on tonal contours. Linguistique Africaine(1), 49-60.

Inkelas, S., \& Zec, D. (1988). Serbo-Croatian pitch accent: the interaction of tone, stress, and intonation. Language, 227-248.

Karlin, R. (2014). The articulatory TBU: Gestural coordination of lexical tone in Thai. (Cornell Working Papers in Phonetics and Phonology)

Kuznetsova, A., Brockhoff, P. B., \& Christensen, R. H. B. (2015). Package lmerTest. $R$ package version, $2(0)$.

Ladd, D. R. (2008). Intonational phonology. Cambridge University Press.

Ladd, D. R., Faulkner, D., Faulkner, H., \& Schepman, A. (1999). Constant "segmental anchoring" of F0 movements under changes in speech rate. The Journal of the Acoustical Society of America, 106 (3 Pt 1), 1543-1554.

Lehiste, I., \& Ivić, P. (1986). Word and sentence prosody in Serbocroatian. MIT Press.

Lenth, R. (2019). emmeans: Estimated marginal means, aka least-squares means [Computer software manual]. Retrieved from https://CRAN.R-project.org/package=emmeans ( $\mathrm{R}$ package version 1.3.5.1)

Marin, S. (2013). The temporal organization of complex onsets and codas in Romanian: A gestural approach. Journal of Phonetics, 41(3-4), 211-227.

Marin, S., \& Pouplier, M. (2010). Temporal organization of complex onsets and codas in American English: testing the predictions of a gestural coupling model. Motor Control, $14(3)$.

McAuliffe, M., Socolof, M., Mihuc, S., Wagner, M., \& Sonderegger, M. (2017). Montreal forced aligner. http://montrealcorpustools.github.io/Montreal-Forced -Aligner/.

Morén, B., \& Zsiga, E. (2006). The lexical and post-lexical phonology of Thai tones. Natural Language \& Linguistic Theory, 24(1), 113-178. 
Mücke, D., Grice, M., Becker, J., \& Hermes, A. (2009). Sources of variation in tonal alignment: evidence from acoustic and kinematic data. Journal of Phonetics, 37(3), 321-338.

Mücke, D., Nam, H., Hermes, A., \& Goldstein, L. (2011). Coupling of tone and constriction gestures in pitch accents. Consonant Clusters and Structural Complexity, 26.

Myers, S. (1999). Tone association and f0 timing in Chichewa. Studies in African Linguistics, $28(2)$.

Myrberg, S. (2010). The intonational phonology of Stockholm Swedish (Unpublished doctoral dissertation). Acta Universitatis Stockholmiensis.

Pierrehumbert, J. B. (1980). The phonology and phonetics of English intonation (Unpublished doctoral dissertation). Massachusetts Institute of Technology.

Prieto, P. (2011). Tonal alignment. In M. van Oostendorp, C. J. Ewen, E. V. Hume, \& K. Rice (Eds.), The Blackwell companion to phonology (pp. 1185-1203). Blackwell Publishing.

Prieto, P., Mücke, D., Becker, J., \& Grice, M. (2007). Coordination patterns between pitch movements and oral gestures in Catalan. In Proceedings of the xvith International Congress of Phonetic Sciences, pirrot gmbh: Dudweiler (pp. 989-992).

R Core Team. (2019). R: A language and environment for statistical computing [Computer software manual]. Vienna, Austria. Retrieved from https://www.R-project.org/

Remijsen, B. (2013). Tonal alignment is contrastive in falling contours in Dinka. Language, $89(2), 297-327$.

Remijsen, B., \& Ayoker, O. G. (2014). Contrastive tonal alignment in falling contours in Shilluk. Phonology, 31(03), 435-462.

Ridouane, R., \& Cooper-Leavitt, J. (2019). A story of two schwas: a production study from Tashlhiyt. Phonology, 36(3), 433-456.

Sagey, E. (1986). The representation of features and relations in autosegmental phonology (Unpublished doctoral dissertation). MIT.

Schweitzer, K., Walsh, M., Calhoun, S., Schütze, H., Möbius, B., Schweitzer, A., \& Dogil, G. (2015). Exploring the relationship between intonation and the lexicon: Evidence for lexicalised storage of intonation. Speech Communication, 66, 65-81.

Shaw, J. A., \& Chen, W.-r. (2019). Spatially-conditioned speech timing: evidence and implications. Frontiers in Psychology, 10, 2726.

Silverman, K., \& Pierrehumbert, J. (1990). The timing of prenuclear high accents in English. Papers in laboratory phonology I, 72-106.

Smiljanić, R. (2002). Lexical, pragmatic and positional effects on prosody in two dialects of Croatian and Serbian: An acoustic study (Unpublished doctoral dissertation). Univer- 
sity of Illinois at Urbana-Champaign.

Turk, A., \& Shattuck-Hufnagel, S. (2020). Timing evidence for symbolic phonological representations and phonology-extrinsic timing in speech production. Frontiers in Psychology, 10(2952), 1-20.

$\mathrm{Xu}, \mathrm{Y}$. (2001). Fundamental frequency peak delay in Mandarin. Phonetica, 58(1-2), 26-52.

$\mathrm{Xu}, \mathrm{Y}$. (2005). Speech melody as articulatorily implemented communicative functions. Speech communication, 46(3), 220-251.

Xu, Y., \& Wang, Q. E. (2001). Pitch targets and their realization: Evidence from mandarin chinese. Speech communication, 33(4), 319-337.

Yi, H. (2014). A gestural account of Mandarin tone sandhi. The Journal of the Acoustical Society of America, 136(4), 2144-2144.

Yi, H. (2017). Lexical tone gestures (Unpublished doctoral dissertation). Cornell University.

Yip, M. (1989). Contour tones. Phonology, 6(01), 149-174.

Yip, M. (2002). Tone. Cambridge University Press.

Yu, A. C. (2010). Tonal effects on perceived vowel duration. In C. Fougeron, B. Kuehnert, M. D'Imperio, \& N. Vallee (Eds.), Laboratory phonology 10 (pp. 151-168). Mouton de Gruyter.

Zec, D. (2005). Prosodic differences among function words. Phonology, 22(1), 77-112.

Zec, D., \& Zsiga, E. (2016). (talk) A new typology of tone and stress interactions. Manchester Phonology Meeting 24.

Zhang, M., Geissler, C., \& Shaw, J. (2019). Gestural representations of tone in Mandarin: evidence from timing alternations. In S. Calhoun, P. Escudero, M. Tabain, \& P. Warren (Eds.), Proceedings of the 19th International Congress of Phonetic Sciences (pp. 18031807).

Zsiga, E., \& Zec, D. (2013). Contextual evidence for the representation of pitch accents in standard Serbian. Language and speech, 56(1), 69-104. 